\title{
Sequential optimization of methotrexate encapsulation in micellar nano-networks of polyethyleneimine ionomer containing redox-sensitive cross-links
}

\author{
This article was published in the following Dove Press journal: \\ International Journal of Nanomedicine \\ 6 June 2014 \\ Number of times this article has been viewed
}

\author{
Samira Sadat Abolmaali' \\ Ali Tamaddon ${ }^{1,2}$ \\ Gholamhossein Yousefi ${ }^{1,2}$ \\ Katayoun Javidnia ${ }^{3}$ \\ Rasoul Dinarvand ${ }^{4}$ \\ 'Department of Pharmaceutics, \\ Shiraz School of Pharmacy, \\ ${ }^{2}$ Center for Nanotechnology in \\ Drug Delivery, ${ }^{3}$ Medicinal and \\ Natural Products Chemistry \\ Research Center, Shiraz University \\ of Medical Sciences, Shiraz, Iran; \\ ${ }^{4}$ Nanotechnology Research Centre, \\ Faculty of Pharmacy, Tehran \\ University of Medical Sciences, \\ Tehran, Iran
}

\begin{abstract}
A functional polycation nanonetwork was developed for delivery of water soluble chemotherapeutic agents. The complexes of polyethyleneimine grafted methoxy polyethylene glycol (PEI-g-mPEG) and $\mathrm{Zn}^{2+}$ were utilized as the micellar template for cross-linking with dithiodipropionic acid, followed by an acidic $\mathrm{pH}$ dialysis to remove the metal ion from the micellar template. The synthesis method was optimized according to $\mathrm{pH}$, the molar ratio of $\mathrm{Zn}^{2+}$, and the cross-link ratio. The atomic force microscopy showed soft, discrete, and uniform nano-networks. They were sensitive to the simulated reductive environment as determined by Ellman's assay. They showed few positive $\zeta$ potential and an average hydrodynamic diameter of $162 \pm 10 \mathrm{~nm}$, which decreased to $49 \pm 11 \mathrm{~nm}$ upon dehydration. The ionic character of the nano-networks allowed the achievement of a higher-loading capacity of methotrexate (MTX), approximately $57 \%$ weight per weight, depending on the cross-link and the drug feed ratios. The nano-networks actively loaded with MTX presented some suitable properties, such as the hydrodynamic size of $117 \pm 16$ $\mathrm{nm}$, polydispersity index of 0.22 , and a prolonged swelling-controlled release profile over 24 hours that boosted following reductive activation of the nanonetwork biodegradation. Unlike the PEI ionomer, the nano-networks provided an acceptable cytotoxicity profile. The drug-loaded nano-networks exhibited more specific cytotoxicity against human hepatocellular carcinoma cells if compared to free MTX at concentrations above $1 \mu \mathrm{M}$. The enhanced antitumor activity in vitro might be attributed to endocytic entry of MTX-loaded nano-networks that was found in the epifluorescence microscopy experiment for the fluorophore-labeled nano-networks.
\end{abstract}

Keywords: nanonetwork, polyethyleneimine, ionomer complex, template assisted synthesis, methotrexate, cytotoxicity

\section{Introduction}

Self-assembled polymeric nanoparticles based on amphiphilic copolymers represent a relatively new class of nanostructures built on the bottom-up technological approach that has attracted considerable attention as a potential delivery vehicle, especially for poorly soluble drugs. ${ }^{1}$ Bottom-up techniques simply arrange building blocks into desirable nanostructures, usually spontaneously, through self-assembly. ${ }^{2}$ Their benefits include particle sizes in the range of 10-200 nm, with a fairly narrow size distribution, simplicity of fabrication as a consequence of the bottom-up approach, and superior loading of active pharmaceutical agents. ${ }^{3}$

A rather new class of the polymer micelles could be prepared through the formation of lyophobic complexes with the polyelectrolyte segment of an ionomer.
Correspondence: Ali Tamaddon Center for Nanotechnology in Drug Delivery, Department of Pharmaceutical Nanotechnology, School of Pharmacy, Shiraz University of Medical Sciences, PO Box 7|345-I583, Shiraz, Iran

Tel +987 II 2424127

Fax +98 7II $2424 I 26$

Email amtamadon@gmail.com 
Ionomers are composed of covalently linked polyelectrolyte and nonionic polymers. ${ }^{4}$ Depending on the topology of linking, they can be classified as block copolymers, graft copolymers, and nano-networks. They behave as unimers like classical polymers or polyelectrolytes in aqueous solution; whereas, the micellization of these ionomers can be induced by external stimuli, such as temperature, $\mathrm{pH}$, ionic strength, or by the complex formation of a polyelectrolyte segment with oppositely charged molecules, such as synthetic linear polyelectrolytes, ${ }^{5,6}$ block ionomers, ${ }^{7}$ surfactants, ${ }^{8,9}$ proteins, ${ }^{10,11}$ deoxyribonucleic acid (DNA), ${ }^{12,13}$ or metal ions. ${ }^{14,15}$

The poly ion metal complexation of ionomers has been used to induce the formation of polymer micelles, as addressed by different authors. The electrostatic neutralization of carboxylate-based polyanionic segments of polyethylene oxide (PEO)-b-polymethacrylic acid, ${ }^{16} \mathrm{PEO}-\mathrm{b}-$ polyacrylic acid (PAA) ${ }^{17,18}$ or pluronic-b-PAA, ${ }^{9,19}$ and alkaline earth metal ions, such as $\mathrm{Ca}^{2+}$ and $\mathrm{Ba}^{2+}$, results in spontaneous micellization of the copolymers.

Alternatively, highly stable, metal-based nanoparticles are prepared through the formation of coordination bonds with transition metal ions. Complexes of hydrophilic block ionomers, such as PAA-b-polyhydroxyethyl acrylate, ${ }^{20}$ PAA-b-polyacrylamide, ${ }^{21}$ or PEO-b-PAA, ${ }^{22}$ and $\mathrm{Al}^{3+}, \mathrm{La}^{3+}$, or $\mathrm{Cu}^{2+}$ lead to the formation of spherical assemblies with core-corona morphology and hydrodynamic diameters in the range of 25-150 $\mathrm{nm}$.

The colloidal stability of ionomer complexes is highly dependent on the environmental parameters, such as $\mathrm{pH}$ and ionic strength. ${ }^{23}$ The low structural stability of ionomer micelles in biological media could be problematic for their biomedical applications. Thus, there is an interest in the stabilization of ionomer micelles by introducing cross-links between the polymer chains, either within the core domain or throughout the corona layer. Bronich et $\mathrm{al}^{14,19}$ developed a procedure in which ionomer micelles were initially prepared by the self-assembly of the ionic blocks of PEO-bpolymethacrylic acid (PMA) or pluronic-PAA copolymers with an oppositely charged condensing agent $\left(\mathrm{Ca}^{2+}\right)$ that was followed by the chemical cross-linking of the ionic blocks in the core by ethylenediamine. Similarly, reversible core-crosslinked micelles were synthesized with cystamine. ${ }^{15}$

Branched polyethyleneimine (PEI) is a cationic polyelectrolyte that contains primary, secondary and tertiary amino groups with the average $\mathrm{pKa}$ value between 8.5-9. ${ }^{24}$ The polymer has a high content of amine nitrogen able to donate electrons and coordinate with transition metal ions. ${ }^{25,26}$ This property may be applied for the immobilization of proteins and enzymes, ${ }^{27-29}$ anchoring metal nanoparticles, ${ }^{30}$ or drug delivery. ${ }^{31,32}$ Different authors have reported ionomer complex micelles of PEI grafted with methoxypolyethylene glycol (mPEG) and anionic surfactants, ${ }^{9,33}$ metal ions $\left(\mathrm{AuCl}_{3}\right.$ or $\left.\mathrm{PtCl}_{6}{ }^{2-}\right),{ }^{26,34}$ oligonucleotides, ${ }^{35}$ or plasmid DNA. ${ }^{36}$ The covalent attachment of $\mathrm{mPEG}$ is commonly used to improve aqueous solubility and to reduce immunogenicity and cytotoxicity of polymeric systems. ${ }^{37,38}$ The different copolymers of PEI and $\mathrm{mPEG}$ form PEI ionomers with a hydrophilic steric shield, which improves the stability of the PEI complexes and prevents aggregation. ${ }^{39}$ The $\mathrm{mPEG}$-grafted PEI has been shown to display decreased interactions with proteins, a reduced activation of the complement system, and an enhanced circulation time in the bloodstream..$^{40}$ Moreover, less safety problems are associated with mPEG grafted than unmodified polymers in vitro and in vivo. ${ }^{41}$

Methotrexate (MTX) is one of the most widely studied and effective therapeutic agents available to treat many solid tumors, hematologic malignancies, and autoimmune diseases; ${ }^{42}$ however, the poor pharmacokinetics, the narrow safety margin, and the impaired cellular uptake of the drug have limited the therapeutic outcomes of conventional delivery systems. Large amounts of the administrated MTX are eliminated by the kidneys within a short period of time, resulting in a short plasma half-life of 5-8 hours and a low drug concentration in target tissues. ${ }^{43}$ Increasing the dose of MTX may result in a higher therapeutic efficacy, but it also leads to a higher risk of side effects; ${ }^{44,45}$ moreover, MTX resistance appears due to impaired cellular uptake. ${ }^{46}$

For an improved MTX delivery, several unique pathophysiological features of the diseases can be used either as targets or as tools for drug delivery, such as angiogenesis, ${ }^{47,48}$ enhanced permeability and retention (EPR) effect, ${ }^{49}$ acidosis, and the expression of specific antigens and receptors. ${ }^{50,51}$ Some delivery systems have been developed to improve the pitfalls of MTX therapy that ranged from polymeric conjugates, such as human serum albumin, liposomes, microspheres, solid lipid nanoparticles, polymeric nanoparticles, dendrimers, polymeric micelles, in situ forming hydrogels, carrier erythrocyte, and nanotechnology-based materials, including carbon nanotubes, magnetic nanoparticles, and gold nanoparticles. They are successful in providing a prolonged and nonfluctuating plasma profile or an enhanced activity in vitro and in vivo; nevertheless, many of them still need different complementary studies to fine-tune the carrier in terms of pharmaceutical properties, as well as safety and efficacy. ${ }^{52}$ 
Following our recent study on the synthesis of homogeneous nano-networks via the core cross-linking of the complexes of $\mathrm{Zn}^{2+}$ and the PEI ionomer and the subsequent removal of $\mathrm{Zn}^{2+}$ from the micellar template, ${ }^{53}$ we aimed to study the application of the developed carrier for the active encapsulation and delivery of MTX in vitro. The effect of different physicochemical and formulation parameters was investigated on colloidal (particle size distribution and morphology) and pharmaceutical (drug-loading and release kinetic) properties of the MTX-loaded nano-networks. It was hypothesized that the cross-linked polyamines core of the nano-networks can encapsulate the negatively charged chemotherapeutic agents, such as MTX, efficiently.

Moreover, the redox-sensitive cross-links can provide the required stability of the nano-networks if they are diluted in the simulated extracellular medium; whereas, the breakdown of the network in the simulated reductive medium can promote the release of the encapsulated MTX. Finally, the cellular internalization of the fluorophore-labeled nanonetwork and the in vitro cellular activity of the MTX-loaded nanonetwork were noticed.

\section{Materials and methods Chemicals}

Branched PEI $10 \mathrm{kDa}$ (corresponding to $\mathrm{M}_{\mathrm{w}} / \mathrm{M}_{\mathrm{n}}$ of 1.4) and mPEG $2 \mathrm{kDa}\left(\mathrm{mPEG}_{2000}-\mathrm{COOH}\right)$ were purchased from Polysciences, Inc., (Warrington, PA, USA) and JenKem Technology USA (Allen, TX, USA), respectively.

MTX (United States Pharmacopeia grade) was obtained from Heumann Pharma GmbH and Co Generica KG (Nürnberg, Germany). Dithiodipropionic acid (DTDP), 1-(3-dimethylaminopropyl)-3-ethylcarbodiimide hydrochloride (EDC), and N-hydroxysuccinimide (NHS), 2,4,6-trinitrobenzene sulfonic acid (TNBS), disodium ethylenediaminetetraacetic acid (EDTA), sodium borohydride (NaBH4), 5,5'-dithiobis-(2-nitrobenzoic acid)
(Ellman's reagent, DTNB), and 3-(4,5-dimethylthiazol2-yl)-2,5-diphenyltetrazolium bromide (MTT) were supplied by Sigma-Aldrich, St Louis, MO, USA. $\mathrm{ZnSO}_{4} \cdot 7 \mathrm{H}_{2} \mathrm{O}$, dichloromethane (DCM), dimethylsulfoxide (DMSO), diethyl ether, triethylamine, 2-morpholinoethanesulfonic acid (MES), and potassium bromide ( $\mathrm{KBr}$ ) were purchased from Merck KGaA (Darmstadt, Germany). Deionized water (Direct Q UV3; EMD Millipore, Billerica, MA, USA) was used for all experiments.

\section{Template-assisted synthesis of nano-networks}

The synthesis method includes the following consecutive steps: PEGylation of PEI; formation of the micellar template of $\mathrm{Zn}^{2+}$ and PEI ionomer; the cross-linking reaction; and the subsequent removal of $\mathrm{Zn}^{2+}$ from the micellar template (Figure 1).

The ionomers composed of branched PEI and grafted $\mathrm{mPEG}-\mathrm{COOH}$ were synthesized by carbodiimide reaction in the presence of triethylamine as a proton quencher, as reported before. ${ }^{54}$ Accordingly, the required volumes of the NHS-activated $\mathrm{mPEG}_{2000}-\mathrm{COOH}$ in methanol reacted with $5 \%$ weight/volume PEI solution in DCM at different nominal ethylene oxide weight ratios $\left(\mathrm{f}_{\mathrm{ETO}}\right.$ ) of $0.1,0.3$, and 0.5 . The reaction media were supplemented with $1 \%$ triethylamine and the required volumes of methanol to obtain the constant volume ratio of methanol/DCM of 2:1. Then, the vessels were incubated for 3 hours while mixing at $25^{\circ} \mathrm{C}$. The products were concentrated using rotational speed-vacuum (RVC 2-18; Martin Christ GmbH, Osterode am Harz, Germany) until a yellowish white wax was obtained. The reconstituted products in deionized water were dialyzed using the Float-A-Lyzer 6-8 kDa (Spectrum Laboratories Inc., Rancho Dominguez, CA, USA), according to the manufacturer's instructions. Then, the product solutions were lyophilized (Alpha 1-2 LD; Martin Christ GmbH). Proton nuclear magnetic resonance

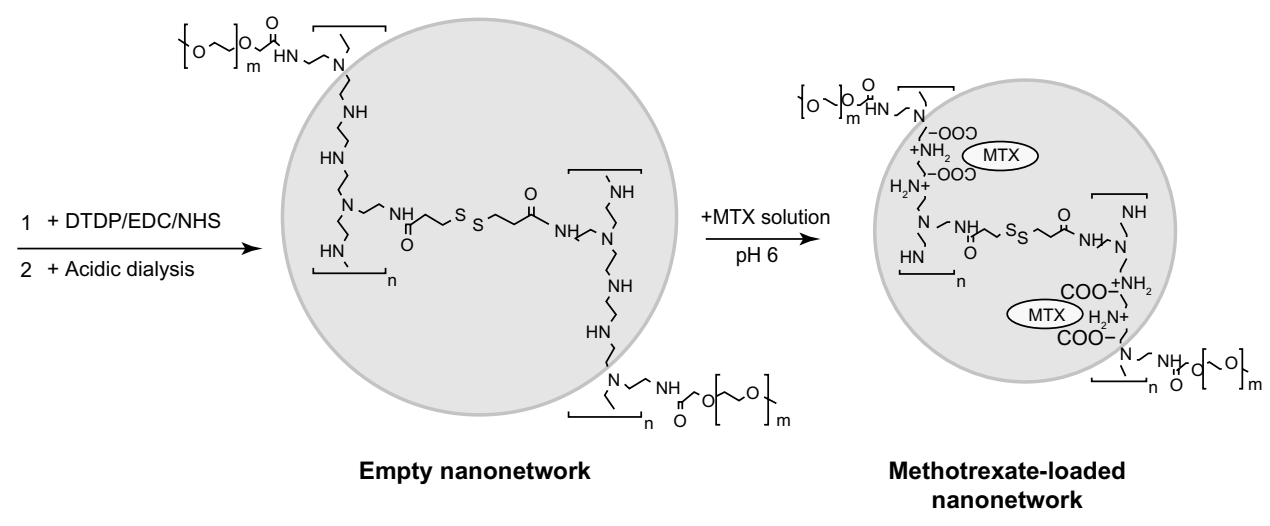

Figure I Schematic presentation of synthesis of empty nano-networks and after loading of MTX.

Abbreviations: DTDP, dithiodipropionic acid; EDC, I-(3-dimethylaminopropyl)-3-ethylcarbodiimide hydrochloride; NHS, N-hydroxysuccinimide; MTX, methotrexate. 
( ${ }^{1} \mathrm{H}-\mathrm{NMR}$ ) spectroscopy was performed for the characterization of the PEI ionomer. It showed multiple peaks at 2.3-3.1 ppm attributed to the ethyleneimine proton and the peak of the ethylene glycol proton at $3.6 \mathrm{ppm}$ in deuterium oxide $\left(\mathrm{D}_{2} \mathrm{O}\right)$ (data not shown). Relative yields of the reactions were about $86 \%-100 \%$.

To prepare complexes of $\mathrm{Zn}^{2+}$ and the PEI ionomers used as a template for the cross-linking reaction, the stock solutions of mPEG-g-branched PEI copolymers (PEI ionomers) were prepared by reconstituting $30 \mathrm{mg}$ of the lyophilized copolymers with the required volumes of deionized water corresponding to the final concentration of $2.3 \mathrm{M}$ total polymer nitrogen. The $\mathrm{ZnSO}_{4}$ was added at different molar ratios of metal ion to the polymer nitrogen $\left(\mathrm{M}^{2+} / \mathrm{N}=0.1,0.4\right.$, and 0.7$)$ at different $100 \mathrm{mM}$ MES buffer $\mathrm{pH}(5,6.5$, and 8) and $\mathrm{NaCl}$ concentrations $(0,50,150 \mathrm{mM})$. The mixtures were vigorously micropipetted several times, incubated at ambient temperature for 30 minutes, and diluted ten times with deionized water. The $\mathrm{L}_{9}$-type Taguchi orthogonal array design was adopted to establish the optimum condition for the preparation of the small and uniform ionomer complexes (Table 1).

Table I Taguchi orthogonal array design

\begin{tabular}{lllllll}
\hline Run & $\mathbf{p H}$ & $\begin{array}{l}\text { Molar ratio } \\
\text { of } \mathbf{Z n}^{2+} / \text { amine }\end{array}$ & $\mathbf{f}_{\mathrm{ETO}}$ & $\begin{array}{l}\mathbf{C}_{\mathbf{N a C l}} \\
(\mathbf{m M})\end{array}$ & $\begin{array}{l}\text { Z-average } \\
(\mathbf{n m})\end{array}$ & PDI \\
\hline 1 & 5.0 & 0.2 & 0.1 & 0 & 121 & 0.57 \\
2 & 5.0 & 0.2 & 0.3 & 50 & 38 & 0.76 \\
3 & 5.0 & 0.2 & 0.5 & 150 & 77 & 0.65 \\
4 & 5.0 & 0.4 & 0.1 & 0 & 166 & 0.43 \\
5 & 5.0 & 0.4 & 0.3 & 50 & 41 & 0.87 \\
6 & 5.0 & 0.4 & 0.5 & 150 & 147 & 0.36 \\
7 & 5.0 & 0.7 & 0.1 & 0 & 183 & 0.30 \\
8 & 5.0 & 0.7 & 0.3 & 50 & 62 & 0.50 \\
9 & 5.0 & 0.7 & 0.5 & 150 & 113 & 0.40 \\
10 & 6.5 & 0.2 & 0.1 & 50 & 34 & 0.53 \\
11 & 6.5 & 0.2 & 0.3 & 150 & 69 & 0.77 \\
12 & 6.5 & 0.2 & 0.5 & 0 & 53 & 0.46 \\
13 & 6.5 & 0.4 & 0.1 & 50 & 1,850 & 0.67 \\
14 & 6.5 & 0.4 & 0.3 & 150 & 1,526 & 0.46 \\
15 & 6.5 & 0.4 & 0.5 & 0 & 710 & 0.62 \\
16 & 6.5 & 0.7 & 0.1 & 50 & 8,350 & 0.31 \\
17 & 6.5 & 0.7 & 0.3 & 150 & 1,235 & 0.48 \\
18 & 6.5 & 0.7 & 0.5 & 0 & 1,067 & 0.57 \\
19 & 8.0 & 0.2 & 0.1 & 150 & 166 & 0.70 \\
20 & 8.0 & 0.2 & 0.3 & 0 & 249 & 0.46 \\
21 & 8.0 & 0.2 & 0.5 & 50 & 110 & 0.58 \\
22 & 8.0 & 0.4 & 0.1 & 150 & 1,047 & 0.40 \\
23 & 8.0 & 0.4 & 0.3 & 0 & 1,756 & 0.72 \\
24 & 8.0 & 0.4 & 0.5 & 50 & 614 & 0.48 \\
25 & 8.0 & 0.7 & 0.1 & 150 & 1,905 & 0.58 \\
26 & 8.0 & 0.7 & 0.3 & 0 & 2,415 & 0.45 \\
27 & 8.0 & 0.7 & 0.5 & 50 & 2,179 & 0.49 \\
\hline
\end{tabular}

Notes: Taguchi orthogonal array design for optimization of Z-average and PDI as functions of $\mathrm{pH}$, the molar ratio of $\mathrm{Zn}^{2+} / \mathrm{amine}$ of $\mathrm{PEl}$ ionomer, the weight fraction of PEO $\left(f_{\mathrm{ETO}}\right)$, and the concentration of $\mathrm{NaCl}(\mathrm{mM})$.

Abbreviations: $\mathrm{PEO}$, polyethylene oxide; PDI, polydispersity index; PEI, polyethyleneimine; $f_{E T O}$, weight fraction of PEO; $C$, concentration.
The cross-linking reaction was achieved via condensation occurring between the reactive amine groups of the copolymers and the carboxylic functional groups of $100 \mathrm{mM}$ DTDP solution in DMSO using EDC and NHS, at the molar ratio 2:2:1 NHS/EDC/COOH. The degree of cross-linking was controlled by the cross-linking ratio $(\mathrm{C})$, defined as the molar ratio of DTDP to primary amines that were studied in three levels $(0.3,0.6$, and 1.2). The reaction mixture was allowed to stir overnight at room temperature. Then, the cross-linked ionomer complexes were dialyzed against the acidic deionized water $(\mathrm{pH}<3)$ using the Float-A-Lyzer (6-8 $\mathrm{kDa}$ ) to remove the $\mathrm{Zn}^{2+}$ template and to prepare the nano-networks.

\section{Dynamic light scattering and $\zeta$ potential}

The intensity-average diameter (Z-average) and polydispersity index (PDI) of the $\mathrm{Zn}^{2+}$-templated ionomer dispersions or the nano-networks were measured at the concentration of 1-2 mg/mL, using a Zetasizer 3000 HSA from Malvern Instruments (Malvern Instruments, Malvern, UK) at a fixed scattering angle of $90^{\circ}$, using a helium-neon laser $(\lambda=633 \mathrm{~nm})$. The PDI is a dimensionless measure of the heterogeneity of particle sizes calculated from a cumulants analysis of the measured intensity autocorrelation function. The viscosity and refractive index of pure water at $25^{\circ} \mathrm{C}$ were used for data analysis. Zeta-potential measurements were performed for $1 / 10$ dilutions of the dispersions in phosphate-buffered saline $(\mathrm{pH}=7.4)$, based on the electrophoretic mobility of the particles in a clear, disposable capillary electrophoresis cell. Values were given as the mean of triplicate samples.

\section{Remote loading of MTX}

The aqueous dispersions of the PEI ionomer $\left(\mathrm{f}_{\mathrm{ETO}}=0.3, \mathrm{C}=0\right)$ and the corresponding nano-networks at different cross-link ratios $(\mathrm{C}=0.3, \mathrm{C}=0.6)$ were simply mixed by pipetting with an aqueous solution of MTX in the deionized water at different ratios of MTX to molar amine moieties of the PEI ionomer $(\mathrm{R}=0.15,0.3$, and 0.6$)$ at different $\mathrm{pH}(5,6$, and 7$)$.

The mixtures were incubated for 72 hours at room temperature while shaking at $400 \mathrm{rpm}$. The unbound MTX was removed by ultrafiltration using Amicon YM-30 centrifugal filter devices (EMD Millipore). The concentration of MTX in filtrates was determined using a Knauer high-performance liquid chromatography (HPLC) system with P1000 pump (Herbert Knauer GmbH, Berlin, Germany) equipped with a multiple wavelength ultraviolet (UV) detector (UV 2600 detector). Separation of MTX was achieved at ambient 
temperature, using monolithic reversed phase column (Chromolith ${ }^{\circledR}$ Guard column, RP-18e, 5-4.6 mm; Merck). The mobile phase was composed of $100 \mathrm{mM}$ sodium acetate $(\mathrm{pH} 4)$ acetonitrile (volume ratio of 88:12) and was delivered isocratically at a flow rate of $2 \mathrm{~mL} /$ minute.

The HPLC method was validated in terms of specificity, linearity, accuracy, precision, and limit of quantification for an in vitro assay. Accordingly, the entrapment efficiency (the percentage of MTX entrapped to the total amount added) and the entrapment capacity (percentage of the entrapped MTX to the total amount of loaded system) were calculated.

The effects of the different factors $(\mathrm{pH}$, feeding ratios, and the cross-link ratios) on the loading parameters were investigated by full factorial design in three levels (Table 2). The factors were analyzed using Design-Expert ${ }^{\circledR}$ Software version 6.02 (Stat-Ease, Inc., Minneapolis, MN, USA).

The particle sizes and $\zeta$ potentials of MTX-loaded nano-networks were determined at different cross-link ratios $(0.0,0.3$, and 0.6$)$ and a constant MTX feed ratio of 0.3 , according to the section "Remote loading of MTX."

\section{Atomic force microscopy}

To explore the morphology of the particles, samples were prepared for atomic force microscopy (AFM) imaging by depositing $10 \mu \mathrm{L}$ of $0.2 \mathrm{mg} / \mathrm{mL}$ aqueous dispersion of empty and MTX-loaded nano-networks $(\mathrm{R}=0.3)$ at different cross-link ratios $(0.3$ and 0.6$)$ in comparison with the complexes of the MTX and the PEI ionomer, onto a prewashed glass slide. The AFM imaging was performed in air using a vibration-damped NanoWizard $^{\circledR}$ II (JPK Instruments AG, Berlin, Germany). Commercial pyramidal tips (MicroMasch Inc., Tartu, Estonia) attached to I-type cantilevers with a length of about $230 \mu \mathrm{m}$, a resonance frequency of about $380 \mathrm{kHz}$, and a nominal force constant of $40 \mathrm{~N} / \mathrm{m}$ were used. Images were recorded in an intermittent contact mode at a scan speed of approximately $1 \mathrm{~Hz}$ to avoid damage of the sample surface. The acquired images had a resolution of $512 \times 512$ pixels. The topological characteristics, including projected diameter (d), surface area $(\mathrm{A})$, perimeter $(\mathrm{P})$, and maximum height $\left(\mathrm{Z}_{\max }\right)$, were measured randomly by the software for at least 300 particles.

Subsequently, the shape factors (circularity and aspect ratio) were calculated according to Equation 1 and Equation 2 to express the morphology of the particles:

$$
\begin{aligned}
& \text { Circularity }=\frac{4 \pi A}{P^{2}} \\
& \text { Aspect ratio }=\frac{d}{Z_{\max }}
\end{aligned}
$$

\section{In vitro release study}

The release of the MTX from the nano-networks prepared at the cross-link ratio of 0.3 was evaluated by the dialysis method at $\mathrm{R}=0.3$ for 24 hours in phosphate buffered saline (PBS; $\mathrm{pH} 7.4 ; 0.14 \mathrm{M} \mathrm{NaCl}$ ) and acetate buffered saline ( $\mathrm{pH} 5.5$; $0.14 \mathrm{M} \mathrm{NaCl}$ ) without or with $1 \mathrm{mM}$ tris(2-carboxyethyl) phosphine (TCEP) as a reducing agent.

Briefly, $4 \mathrm{~mL}$ MTX-loaded nano-networks containing $2.5 \mathrm{mg}$ of the PEI ionomer and $1.4 \mathrm{mg}$ of MTX were placed in the Float-A-Lyzer 6-8 kDa dialysis tube. The dialysis was carried out against $400 \mathrm{~mL}$ of the release media in a shaking incubator at $37^{\circ} \mathrm{C}$ and $100 \mathrm{rpm}$.

At scheduled times, $1 \mathrm{~mL}$ of the medium was withdrawn, and the amount of MTX released was estimated by the HPLC method as described in the section "Remote loading of MTX." The cumulative release percentage of MTX was determined at each point and plotted as a function of time.

\begin{tabular}{|c|c|c|c|c|c|}
\hline Formulation & $\begin{array}{l}\text { Cross-link } \\
\text { ratio }\end{array}$ & Condition & $\begin{array}{l}\text { Z-average } \\
(\mathrm{nm})\end{array}$ & PDI & $\begin{array}{l}\text { Zeta potential } \\
(\mathrm{mV})^{*}\end{array}$ \\
\hline I & 0 & $+\mathrm{Zn}^{2+}$ & $33.7 \pm 6.4$ & $0.22 \pm 0.07$ & - \\
\hline 2 & 0.3 & $+\mathrm{Zn}^{2+}$ & $112.8 \pm 42.6$ & $0.14 \pm 0.11$ & - \\
\hline 3 & 0.6 & $+\mathrm{Zn}^{2+}$ & $139.6 \pm 11.5$ & $0.24 \pm 0.06$ & - \\
\hline 4 & 1.2 & $+\mathrm{Zn}^{2+}$ & $227.3 \pm 12.5$ & $0.30 \pm 0.01$ & - \\
\hline 5 & 0.3 & After acid dialysis & $254.0 \pm 46.6$ & $0.36 \pm 0.06$ & $+9.7 \pm 3.7$ \\
\hline 6 & 0.6 & After acid dialysis & $162.0 \pm 10.0$ & $0.27 \pm 0.04$ & $+1.7 \pm 4.1$ \\
\hline 7 & 1.2 & After acid dialysis & $175.0 \pm 0.0$ & $0.47 \pm 0.02$ & $-0.1 \pm 3.4$ \\
\hline 8 & 0.00 & + MTX & $109.0 \pm 16.8$ & $0.18 \pm 0.06$ & $+5.5 \pm 9.9$ \\
\hline 9 & 0.3 & + MTX & $117.0 \pm 15.9$ & $0.22 \pm 0.01$ & $-1.5 \pm 4.8$ \\
\hline 10 & 0.6 & + MTX & $|33.0 \pm 2| .4$ & $0.19 \pm 0.02$ & $-0.1 \pm 4.5$ \\
\hline
\end{tabular}

Table 2 Z-average, PDI, and zeta-potential of PEl ionomer

Notes: The Z-average, PDI, and zeta-potential of the PEl ionomer at different cross-link ratios before and after the removal of $\mathrm{Zn}^{2+}$ from the micellar templates and following the encapsulation of the MTX in the nano-networks at the feeding ratio of 0.3. *In PBS (I0 mM phosphate salts $+140 \mathrm{mM} \mathrm{NaCl}$; $\mathrm{pH} 7.4$ ).

Abbreviations: PDI, polydispersity index; PEI, polyethyleneimine; MTX, methotrexate; PBS, phosphate buffered saline. 
The control experiment was done to study free MTX transport through the dialysis membrane at the simulated media. To find out the mechanism of drug release from the nano-networks, the Korsmeyer-Peppas equation (Equation 3) was best fitted for the first $60 \%$ drug release data in comparison to other mathematical equations, including zero order, first order, and the Higuchi models. ${ }^{55}$ The release rate $(\mathrm{k})$, the release exponent $(\mathrm{n})$, and the lag time $\left(\mathrm{t}_{0}\right)$ were determined from the fraction of MTX released $\left(\mathrm{M} / \mathrm{M}_{\infty}\right)$ versus time $(\mathrm{t})$ by a nonlinear regression method, using SPSS Statistics version 16.0 (IBM Corporation, Armonk, NY, USA).

$$
\frac{\mathrm{M}}{\mathrm{M}_{\infty}}=\mathrm{k} \cdot\left(\mathrm{t}-\mathrm{t}_{0}\right)^{\mathrm{n}}
$$

\section{Redox-sensitive degradation}

To study the redox biodegradability of the nano-networks, the thiol content of the cross-linked nanoparticles was determined prior to and after reducing the disulfide bond present in the DTDP molecule, according to the published method. ${ }^{56}$

Briefly, $25 \mu \mathrm{L}$ of the $0.2 \mathrm{M} \mathrm{NaBH}_{4}$ solution in $\mathrm{NaOH}$ $0.2 \%$ was added to $45 \mu \mathrm{L}$ of the sample solutions, which contained $4 \mathrm{mM}$ nitrogen, and incubated for 1 hour at room temperature while shaking at $300 \mathrm{rpm}$. Then, $\mathrm{pH}$ was adjusted to 4 using $\mathrm{HCl} 1 \mathrm{~N}$ and further incubated for 10 minutes to remove the $\mathrm{NaBH}_{4}$ from the reaction medium. The medium was supplemented with $\mathrm{NaOH} 1 \mathrm{~N}$ to adjust the $\mathrm{pH}$ again to 8 . The volume reached $90 \mu \mathrm{L}$ with the addition of (4-(2hydroxyethyl)-1-piperazineethanesulfonic acid) (HEPES) buffer (300 mM; pH 8.0). Then, $10 \mu \mathrm{L}$ (4 mg/mL) DTNB in the HEPES buffer (50 mM; pH 8.0) was added, and the mixture was incubated for 15 minutes at room temperature. Absorbance values were obtained with a PowerWave HT microplate reader (BioTek, Winooski, VT, USA) at $\lambda=412$ $\mathrm{nm}$, and the thiol content was calculated using a standard curve of the reduced glutathione and expressed as mmol/L free thiol.

\section{In vitro cellular studies}

The MTT-based cytotoxicity assay was carried out based on the protocol described previously. ${ }^{57}$ Accordingly, the HepG2 cells were plated into 96-well microtiter plates (Orange Scientific, Braine-1'Alleud, Belgium) at a density of 25,000 cells $/ \mathrm{cm}^{2}$. After 24 hours, the cells were treated in serum-supplemented culture medium. First, the assay was performed for the nano-networks at the cross-link ratios of 0.3 and 0.6 , in comparison to the PEI ionomer and the branched PEI $\left(\mathrm{M}_{\mathrm{w}}=10 \mathrm{kDa}\right)$. In another experiment, the cytotoxicity of MTX was determined in HepG2 cells incubated with the free drug for 24, 48, and 72 hours. Finally, the cytotoxicity of the MTX-loaded nano-networks was compared to the free MTX after 24 hours. Each treatment was similarly prepared by the primary dilution of the stock solutions in phosphate buffered saline (pH 7.4) and the final $10 \times$ dilution in RPMI 1640 medium (PAA Laboratories GmbH, Germany) supplemented with $10 \%$ fetal bovine serum (Gibco BRL).

Following incubation, the medium was aspirated and replaced by $100 \mu \mathrm{L}$ of $1 / 10$ diluted MTT stock solution in the culture medium to obtain the final concentration of $0.5 \mathrm{mg} / \mathrm{mL}$. After 3 hours, the medium was aspirated again, and the insoluble formazan crystals were dissolved in $100 \mu \mathrm{L} /$ well DMSO and measured spectrophotometrically in a microplate reader at $\lambda=570 \mathrm{~nm}$, and corrected for background absorption at $\lambda=650 \mathrm{~nm}$. Cell viability was calculated for blank-corrected data relative to untreated control cells.

To determine cellular uptake potential of the nanonetworks, the cells were grown on Lab-Tek II 4-well chamber slides with covers (Nunc, USA Scientific, Ocala, FL, USA) at a density of $2 \times 10^{4}$ cells per chamber. The cells were treated with $50 \mu \mathrm{g} / \mathrm{mL}$ of nano-networks labeled with fluorescein isothiocyanate (FITC), washed three times with cold PBS, fixed with 3.7\% paraformaldehyde solution in PBS at $4^{\circ} \mathrm{C}$ for 15 minutes, followed by washing with PBS. Cellular internalization of the nanohydrogels was studied by epifluorescence microscope (Nikon Eclipse E400; Nikon Corporation, Tokyo, Japan).

\section{Statistics}

The statistical analysis was performed by GraphPad Software Inc., version 5.0 (GraphPad Software, Inc., La Jolla, CA, USA). $P$-values $>0.05$ were considered statistically significant. Data were expressed as mean \pm standard deviation.

\section{Results and discussion Template-assisted synthesis of nano-networks}

The preparation method requires a low-energy mixing process, and it does not require the use of any organic solvent. The donor-acceptor complexes of $\mathrm{Zn}^{2+}$ and the amines of the PEI ionomers can be considered as a special type of copolymer with lyophobic segments formed from the phase separation of the ethyleneimine moieties with $\mathrm{Zn}^{2+}$. The water-soluble mPEG segments stabilize the coacervates and prevent the aggregation or the macroscopic phase separation. 
Similarly, the formation of metal colloids has been shown in aqueous medium by the reduction of the lyophobic complexes of diblock or graft PEO-PEI with $\mathrm{Pd}^{2+}$ or $\mathrm{Pt}^{2+}$ at low $\mathrm{pH}^{25,34}$ The preparation requires a precise tuning of different physicochemical parameters, such as $\mathrm{f}_{\mathrm{ETO}}, \mathrm{pH}$, the ionic strength of the solution, and the type and the concentration of the ionic species, inducing the gelation of ionomers. ${ }^{23,58}$ Therefore, it was hypothesized that the colloid property of the complexes of PEI ionomers with $\mathrm{Zn}^{2+}$ depends on some factors such as $\mathrm{pH}$, the molar ratio of $\mathrm{Zn}^{2+}, \mathrm{f}_{\mathrm{ETO}}$, and salt concentration. The factors were considered in the Taguchi orthogonal array design for optimization of the size distribution. The Taguchi method is a fractional factorial design proposed by Genichi Taguchi, a Japanese engineer, to improve the quality of products or processes.

Accordingly, the particle size data (Z-average and PDI) were analyzed statistically by changing the experimental factors simultaneously, according to the designed array in three levels (Table 1). The data were successfully fitted in individual two-factor interaction models $(P<0.0001$ and $P<0.05$, respectively).

If the $\mathrm{Z}$-average was considered as a response variable, $\mathrm{pH}(P<0.0001)$, the molar ratio of $\mathrm{Zn}^{2+}(P<0.0001)$, and their interaction ( $P$ approximately 0.001$)$ were determined significant. Figure $2 \mathrm{~A}$ shows the sizes increased abruptly if the molar ratio of $\mathrm{Zn}^{2+}$ increased from 0.2 , possibly due to an insufficiency of $\mathrm{mPEG}$ chains to solubilize the lyophobic PEI- $\mathrm{Zn}^{2+}$ domains. Similarly, it was shown that the aggregation occurs for the block ionomer of polyacrylic acid at a relatively high concentration of $\mathrm{Ba}^{2+}$ and $\mathrm{Gd}^{3+} .{ }^{59}$ The particles enlarged by increasing $\mathrm{pH}$ from 5-6.5, especially at the molar ratios of $\mathrm{Zn}^{2+} \geq 0.4$ (Figure 2B). This could be explained by the reduced protonation of the PEI backbone at a more basic $\mathrm{pH}$, and the very low solubility of the $\mathrm{Zn}^{2+}$ complexes, due to the binding of the hydroxyl ion ligands.

The main effect of the molar ratio of $\mathrm{Zn}^{2+}(P<0.05)$ and the related interaction effect with salt concentration $(P<0.05)$ were statistically significant terms influencing PDI. A relatively high level of the molar ratio of $\mathrm{Zn}^{2+}$ resulted in more homogeneous particles that might occur due to the crosslink action of $\mathrm{Zn}^{2+}$, though the PDI values were still high. An increase of the salt concentration brought about a higher PDI at the low level of $\mathrm{Zn}^{2+}$; however, the lowest PDI was attained at the high level of salt concentration $(150 \mathrm{mM})$ if the molar ratio of $\mathrm{Zn}^{2+}$ was 0.4 . This controversial effect of salt concentration might be due to displacement of $\mathrm{Zn}^{2+}$ from their complexes at the high $\mathrm{NaCl}$ concentration during the phaseseparation step. This phenomenon was reported previously
A
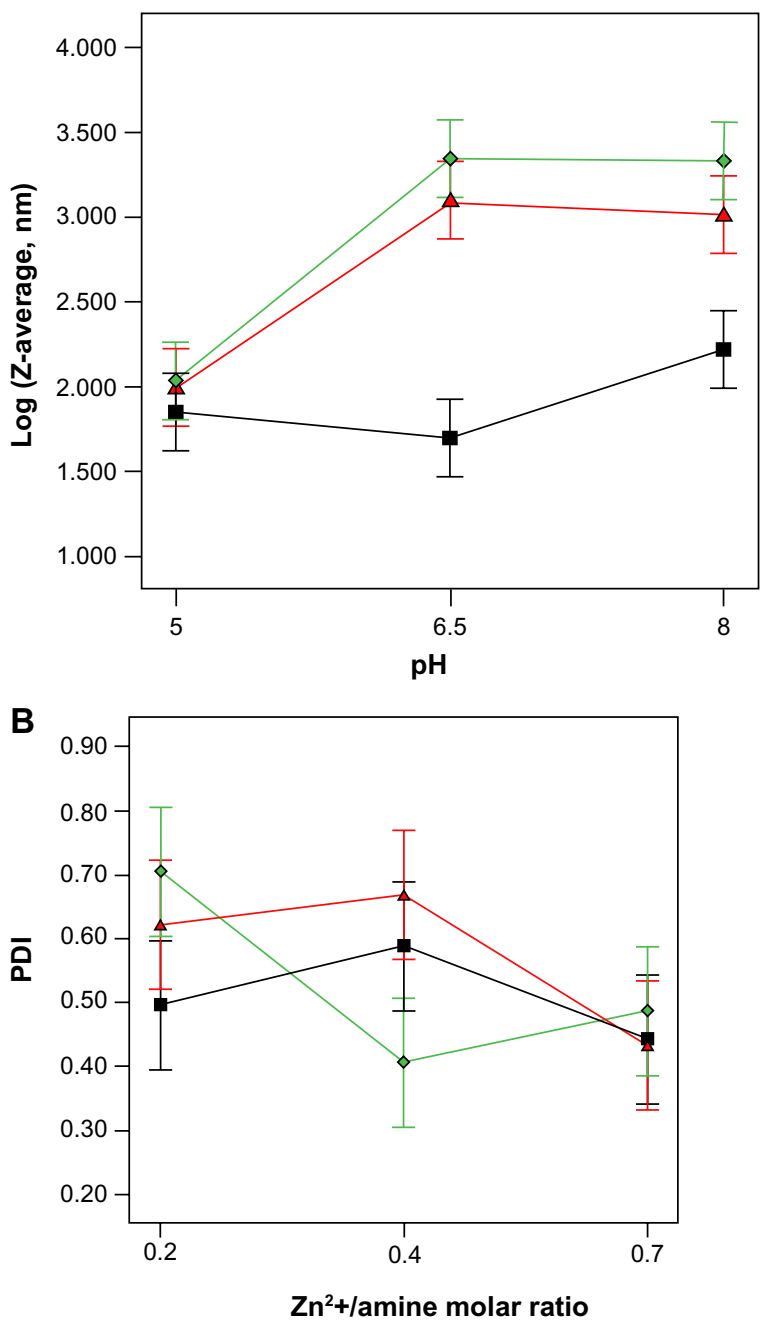

Figure 2 Interaction effect of $\mathrm{pH}$ and the molar ratio of $\mathrm{Zn}^{2+}$ on $\mathrm{Z}$-average $(\mathbf{A})$ and PDI (B) of the PEl ionomer micellar template $\mathbf{\square}, \mathbf{\Delta}$, and $\diamond$ denote various molar ratios of $\mathrm{Zn}^{2+} / \mathrm{amines}$ of the $\mathrm{PEl}$ ionomer $(0.2,0.4$, and 0.7 , respectively). Abbreviations: PDI, polydispersity index; PEl, polyethyleneimine.

for PEO-g-PEI/surfactant complexes. ${ }^{60,61}$ Nevertheless, the salt might stabilize the lyophobic complexes of $\mathrm{Zn}^{2+}$ at the molar ratio of 0.4 , possibly through the formation of the salt bridges on the interface of the lyophobic complexes.

The optimum condition defined by the minimum Z-average $\times$ PDI comprises the molar ratio of $\mathrm{Zn}^{2+}=0.2$, $\mathrm{pH}=5.7, \mathrm{f}_{\mathrm{ETO}}=0.3$, and without additional salt. The resulted self-assembly exhibited Z-average of $33.7 \mathrm{~nm}$ and PDI of 0.22 and served as a micellar template for synthesis of crosslinked polymer micelles in the next step.

Cross-linking of the polyamine core of the micellar template was achieved via condensation reaction with the carboxylic functional groups of DTDP, a homobifunctional carboxylic acid based electrophilic cross-linking reagent with a length of $1.2 \mathrm{~nm}$ and a cleavable disulfide linkage. Following 
the reaction, acid dialysis was performed to remove $\mathrm{Zn}^{2+}$. The ${ }^{1} \mathrm{H}-\mathrm{NMR}$ spectra of the nano-networks showed the total integral intensity of the signals due to $-\mathrm{S}-\mathrm{CH}_{2} \mathrm{CH}_{2}-\mathrm{C}=\mathrm{O}$ protons of DTDP ( $\mathrm{m}, \delta: 2.4-2.9)$ increased by the cross-link ratio in comparison to the ethylene glycol peak of the PEI ionomers in the swollen state (data not shown). The estimated degree of cross-links per primary amines with the nominal cross-link ratio of 0.3 was calculated as $7.36 \%$. This value gradually increased and reached $15.72 \%$ for the nominal cross-linking ratio of 1.2. It is noteworthy to mention that DTDP can also form a loop within a single chain; therefore, the calculated degrees of cross-linking can be overestimated.

Figure $3 \mathrm{~A}$ shows the sizes increased after removing $\mathrm{Zn}^{2+}$ to about $150-250 \mathrm{~nm}$ at the relatively lower cross-link ratios $(0.3$ and 0.6$)$. These observations are consistent with

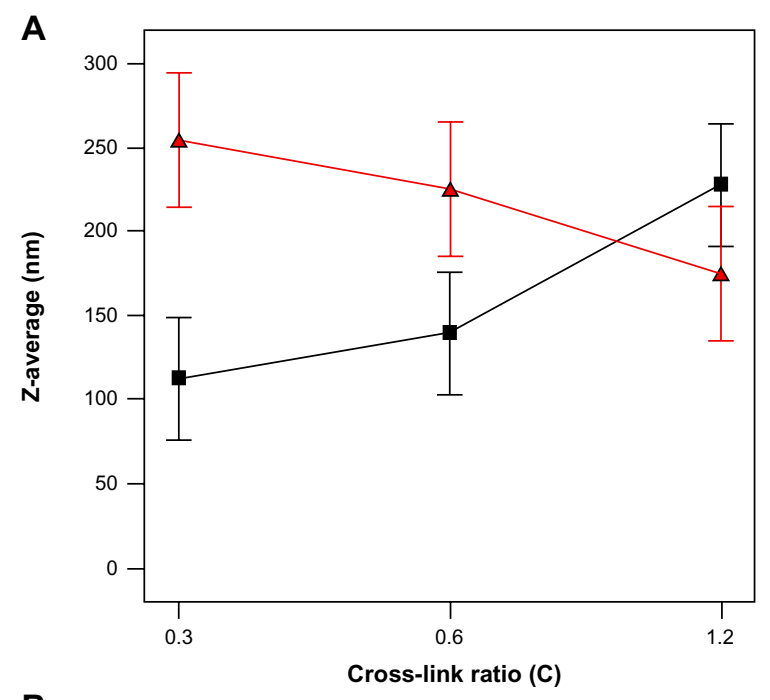

B

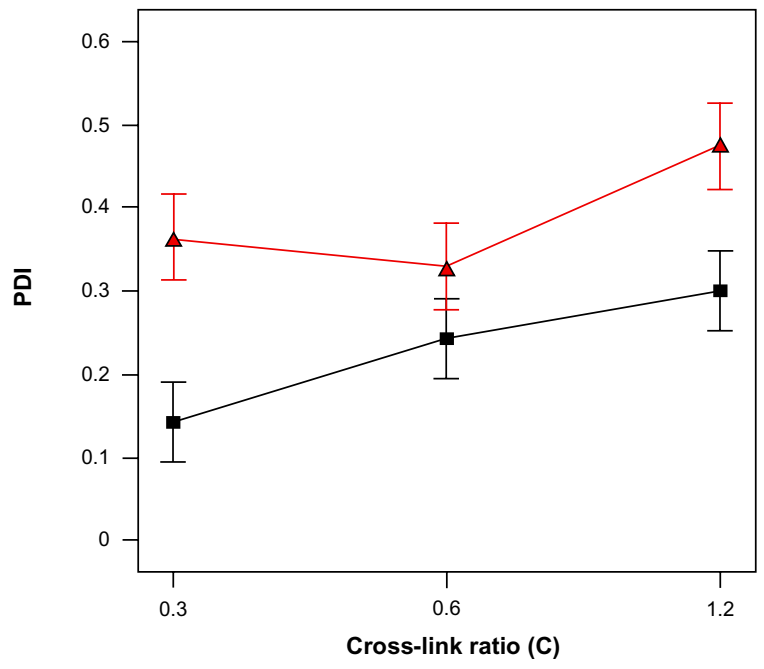

Figure 3 Effect of the cross-link ratio.

Notes: The effect of the cross-link ratio on Z-average (A) and PDI (B) of the $\mathrm{Zn}^{2+}$ micellar template of the PEl ionomer, prior to $(\boldsymbol{\nabla})$ and after $(\boldsymbol{\Delta})$ removal of $\mathrm{Zn}^{2+}$. Abbreviations: PDI, polydispersity index; PEl, polyethyleneimine. the swelling nature of the nano-networks. It was understood from Table 2 that the average volumes of the swollen nanonetworks changed more than ten times upon the removal of $\mathrm{Zn}^{2+}$ at $\mathrm{C}=0.3$, while the volumes exhibited only a modest increase at the higher ratios compared to those of the precursor complexes of $\mathrm{Zn}^{2+}$ and PEI ionomer. The average sizes of the nano-networks decreased by increasing $\mathrm{C}$ from $0.3-1.2$.

This is in line with other studies that showed that if the cross-link ratio increased, the smaller particles of PEO-bPAA were prepared. ${ }^{15,16}$ Nevertheless, the average sizes of the cross-linked complexes of the $\mathrm{Zn}^{2+}$ and the PEI ionomer increased markedly at the cross-link ratio of 1.2 before removing $\mathrm{Zn}^{2+}$ from the micellar templates. This could be explained by an increase of the hydrophobicity of PEI ionomer/ $\mathrm{Zn}^{2+}$ complexes, due to the amide bond formation mediated by DTDP and the failure of the MPEG chains to prevent aggregation.

Figure 3B shows that an increase of PDI happened upon the removal of $\mathrm{Zn}^{2+}$ that was less pronounced at $\mathrm{C}=0.6$. The changes of PDI could be explained by the positive physical cross-link action of $\mathrm{Zn}^{2+}$, which disappeared after acid dialysis. Taking into consideration these results, the synthesis method produces a hydrophilic network with a relatively more uniform population of small particles if compared to other methods, such as polyionic complexation, desolvation, emulsion droplet coalescence, and direct cross-linking. ${ }^{62}$

\section{Remote loading of MTX}

MTX, a weak bicarboxylic acid with pKa values of 3.8 and 4.8 , could be immobilized into the PEI nano-networks (apparent pKa approximately 8.5 ) by the simple mixing of the MTX solution with the aqueous dispersions of the nano-networks. Although it seems that the MTX loading was mainly governed through electrostatic charge complexation, we cannot exclude the possibility that the drug molecules can be physically entrapped and retained in the networks, due to nonspecific hydrophobic interactions.

Table 3 shows full-factorial design optimization of the MTX loading into the nano-networks. The drug loading was expressed as a function of $\mathrm{pH}, \mathrm{C}$ and the $\mathrm{R}$ in terms of the loading efficiency ( $\mathrm{LE} \%$ ) and the loading capacity ( $\mathrm{LC} \%)$. The results of analysis of variance revealed that MTX loading follows the two-factor interaction statistical model $(P<0.0001$ similarly for $\mathrm{LE} \%$ and $\mathrm{LC} \%)$. The main effects of $\mathrm{C}$ and $\mathrm{R}$ and their interaction $(\mathrm{C} \times \mathrm{R})$ were determined as the significant terms included in the corresponding models. 
Table 3 Full factorial design optimization of MTX loading

\begin{tabular}{|c|c|c|c|c|c|}
\hline Run & $\begin{array}{l}\text { Cross-link } \\
\text { ratio }\end{array}$ & $\mathrm{pH}$ & $\begin{array}{l}\text { Feeding } \\
\text { ratio }\end{array}$ & $\begin{array}{l}\text { Loading } \\
\text { efficiency (\%) }\end{array}$ & $\begin{array}{l}\text { Loading } \\
\text { capacity (\%) }\end{array}$ \\
\hline I & 0.0 & 5.0 & 0.15 & 57.67 & 37.20 \\
\hline 2 & 0.0 & 5.0 & 0.30 & 59.81 & 55.13 \\
\hline 3 & 0.0 & 5.0 & 0.60 & 40.22 & 62.28 \\
\hline 4 & 0.0 & 6.0 & 0.15 & 91.83 & 48.54 \\
\hline 5 & 0.0 & 6.0 & 0.30 & 55.85 & 53.43 \\
\hline 6 & 0.0 & 6.0 & 0.60 & 27.27 & 52.82 \\
\hline 7 & 0.0 & 7.0 & 0.15 & 87.03 & 47.20 \\
\hline 8 & 0.0 & 7.0 & 0.30 & 48.22 & 49.76 \\
\hline 9 & 0.0 & 7.0 & 0.60 & 21.94 & 47.39 \\
\hline 10 & 0.3 & 5.0 & 0.15 & 59.87 & 38.08 \\
\hline II & 0.3 & 5.0 & 0.30 & 57.13 & 53.99 \\
\hline 12 & 0.3 & 5.0 & 0.60 & 52.73 & 68.40 \\
\hline 13 & 0.3 & 6.0 & 0.15 & 58.10 & 37.37 \\
\hline 14 & 0.3 & 6.0 & 0.30 & 57.25 & 54.04 \\
\hline 15 & 0.3 & 6.0 & 0.60 & 39.96 & 62.13 \\
\hline 16 & 0.3 & 7.0 & 0.15 & 70.49 & 42.00 \\
\hline 17 & 0.3 & 7.0 & 0.30 & 67.53 & 58.11 \\
\hline 18 & 0.3 & 7.0 & 0.60 & 39.93 & 62.11 \\
\hline 19 & 0.6 & 5.0 & 0.15 & 29.04 & 22.97 \\
\hline 20 & 0.6 & 5.0 & 0.30 & $36.4 I$ & 42.79 \\
\hline 21 & 0.6 & 5.0 & 0.60 & 20.83 & 46.10 \\
\hline 22 & 0.6 & 6.0 & 0.15 & 46.59 & 32.37 \\
\hline 23 & 0.6 & 6.0 & 0.30 & 54.42 & 52.78 \\
\hline 24 & 0.6 & 6.0 & 0.60 & 31.17 & 56.13 \\
\hline 25 & 0.6 & 7.0 & 0.15 & 47.98 & 33.01 \\
\hline 26 & 0.6 & 7.0 & 0.30 & 48.38 & 49.85 \\
\hline 27 & 0.6 & 7.0 & 0.60 & 33.12 & 57.62 \\
\hline
\end{tabular}

Notes: Full factorial design optimization of methotrexate loading, according to the cross-link ratio, $\mathrm{pH}$, and the feeding ratio in three levels.

Abbreviation: MTX, methotrexate.

Figure 4A shows that an increase of $\mathrm{R}$ led to a significant decline of LE\% of the PEI ionomer ( $P=0.001)$, while LE\% was little changed by $\mathrm{R}$ for the nano-networks; however, Figure $4 \mathrm{~B}$ shows that $\mathrm{LC} \%$ was almost constant for the PEI ionomer $(P>0.05)$, but increased for the nano-networks $(P=0.001)$. The increase was more pronounced for $\mathrm{R}$ in the range of 0.15 and 0.30 , but less at $\mathrm{R}=0.6$, possibly due to reduced binding sites for MTX loading.

Remarkably, the LC\% in the PEI ionomer was lower than the nano-networks at $\mathrm{R}=0.6$. It could be explained by the formation of the hydrophobic MTX-bound domains in the polyionic segment of the PEI ionomer stabilized by the $\mathrm{mPEG}$ chains that could lead to a self-assembly, preventing the further loading of MTX molecules. Unlike the PEI ionomer, hollow spaces of the nano-networks provide the free diffusion of MTX molecules, so the interaction of MTX with the outer layer amines does not restrict the subsequent loading.

Higher degrees of cross-linking may lead to a decreased LC\% (Figure 4B and C) as reported before for the cross-linked PEO-b-PMA micelles. ${ }^{16}$ The $\mathrm{pH}$ changes provide
A

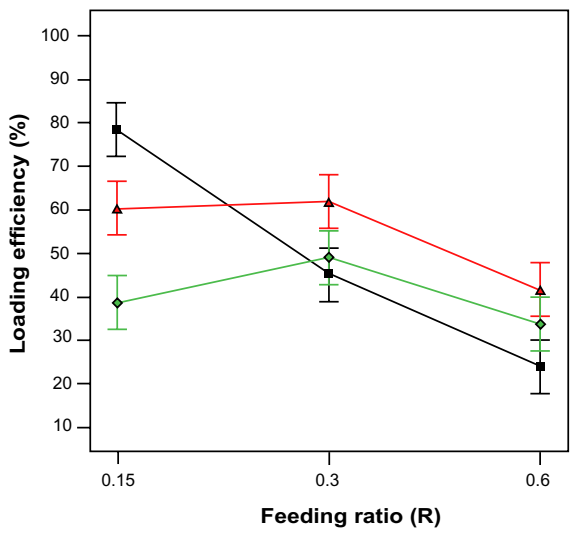

B

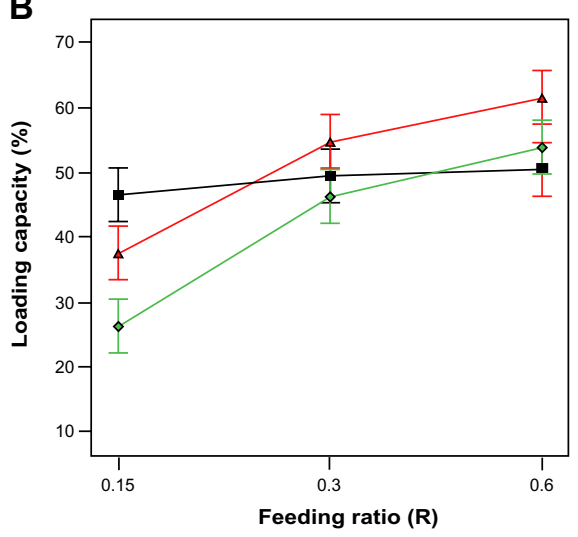

C

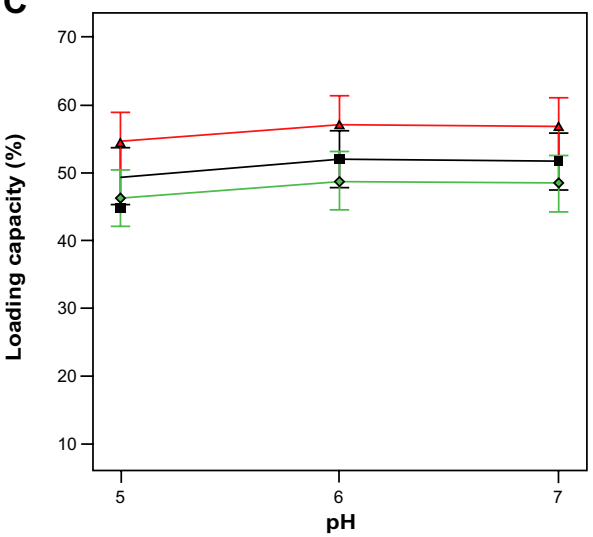

Figure 4 Loading efficiency and loading capacity.

Notes: The loading efficiency \% (A) and loading capacity \% (B and C) of the MTXloaded nano-networks at different cross-link ratios: $\mathbf{0}(0), \boldsymbol{\Delta}(0.3)$, and $(0.6)$ The loading parameters were shown as a function of MTX-feeding ratio ( $\mathbf{A}$ and $\mathbf{B})$ or $\mathrm{pH}(\mathbf{C})$.

an opportunity to tune the electrostatic binding between the MTX and the ionomer chains. LC\% did not change by $\mathrm{pH}$ in the range of 5-7, since the MTX molecule has a similar negative-charge density in that $\mathrm{pH}$ range, and the polymer chain is protonated in the same way at $\mathrm{pH}=5-7$. Both the optimum $\mathrm{LE} \%$ and $\mathrm{LC} \%$ were achieved at the average $\mathrm{pH}$ of 6 and $\mathrm{R}=0.3$ for the nano-networks, especially at $\mathrm{C}=0.3$. 
The optimum LC\% of $57 \%$ was noticeably higher than the previous report of $12 \%,{ }^{63}$ so the nano-networks satisfactorily loaded MTX.

Table 2 shows that MTX loading was accompanied by reduction of the $\mathrm{Z}$-average of the nano-networks especially at the low cross-link ratio $(\mathrm{C}=0.3)(P<0.05)$, suggesting that the drug loading attenuated swelling of the nano-networks through formation of charge-neutralized hydrophobic domains; moreover, the drug loading did not cause any adverse effect on the particle stability.

Notably, the MTX-loaded nano-networks exhibited almost zero value of zeta potential, suggesting that MTX was effectively neutralized by the core amines; nevertheless, nano-networks showed only few positive charges that reduced by increasing the cross-link ratio. The reduced zeta potentials are possibly due to an arrangement of the $\mathrm{MPEG}$ chains around the cross-linked polyamine core that shifts the shear plane away from the positive core, as indicated before. ${ }^{64}$

\section{AFM}

An AFM experiment was performed to investigate topological properties of the empty and the MTX-loaded nano-networks $(\mathrm{R}=0.3)$ at $\mathrm{C}=0.3$ (cross-link 1) and 0.6 (cross-link 2) compared to the complex of the PEI ionomer and the MTX. As shown in Figure 5, discrete, small, and round particles were observed for the nano-networks at $\mathrm{C}=0.6$ that were smaller and more uniform than the complexes of the ionomer and the MTX. Table 4 shows that the average projected diameters of dehydrated empty nano-networks decreased to about $50 \mathrm{~nm}$, if compared to the hydrodynamic diameters as determined by Zetasizer. After loading the MTX into the nano-networks, the diameters and the $\mathrm{Z}$-values increased significantly $(P<0.05)$, as compared to the empty particles. The average circularity of the empty nanonetwork $(\mathrm{C}=0.3 ; \mathrm{R}=0)$ increased significantly $(P<0.05)$

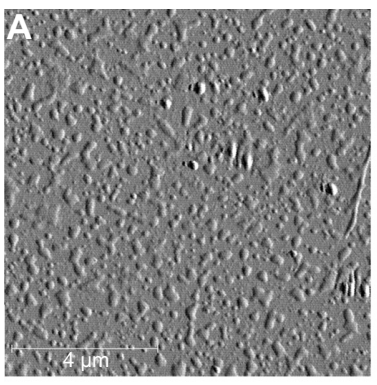

PEI ionomer - MTX complex

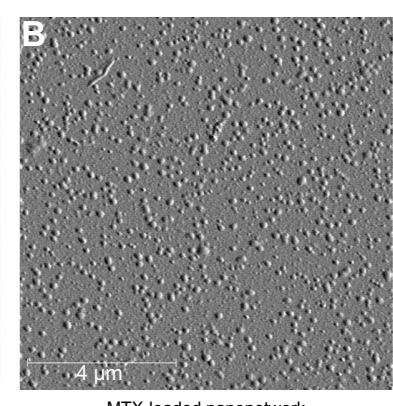

MTX-loaded nanonetwork
Figure 5 AFM images of the methotrexate-loaded PEl ionomer complex (A) and the nano-networks loaded with MTX at the nominal cross-link ratio of 0.6 (B). Abbreviations: AFM, atomic force microscopy; PEl, polyethyleneimine; MTX, methotrexate.

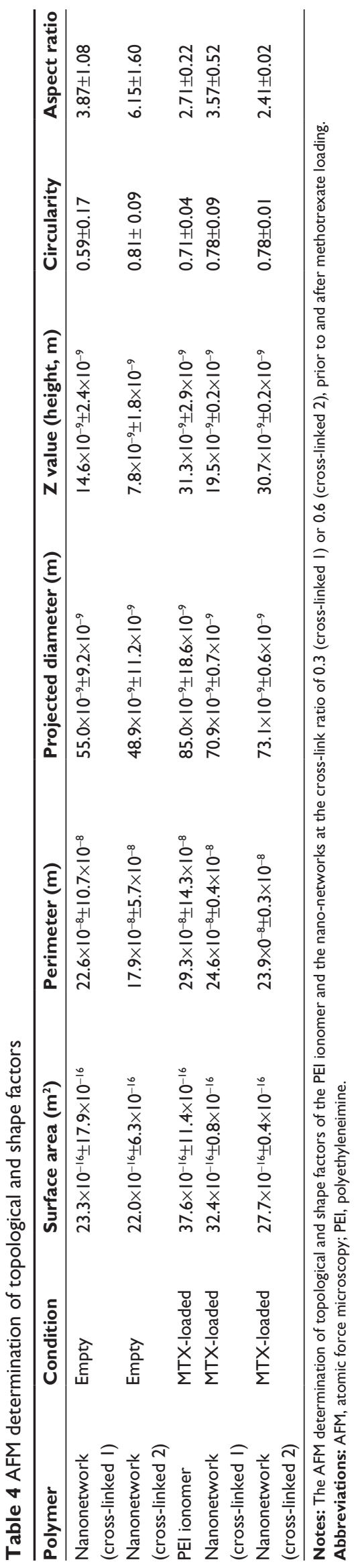


from $0.59-0.78(\mathrm{C}=0.6 ; \mathrm{R}=0)$ and $0.81(\mathrm{C}=0.3 ; \mathrm{R}=0.3)$ in a similar pattern that could be explained by the formation of more homogeneous and spherical particles. Upon adsorption of the nano-networks on a glass surface, they exhibited a high aspect ratio, suggesting that the particles were flattened on the substrate as previously addressed. ${ }^{59}$

\section{In vitro release study}

Figure 6 shows the release profiles of the MTX loaded nano-networks $(\mathrm{C}=0.6 ; \mathrm{R}=0.3)$ in isotonic-balanced release media ( $\mathrm{pH} 5.5$ or $7.5+140 \mathrm{mM} \mathrm{NaCl}$ ). A prolonged release of MTX achieved over 24 hours is consistent with the previous reports of a sustained MTX release for 8-24 hours. ${ }^{65,66}$ No burst release or very significant lag-time was recognized
$(P>0.05)$ for the MTX-loaded nano-networks if compared to free MTX, although the initial burst behavior has been reported in several studies, due to the fast escape of the free MTX out of the nanoparticles. ${ }^{67,68}$ The better control of the initial burst release might be explained by the formation of a core-enriched model of an active MTX loading within the closely packed amine moieties. The release data were analyzed, according to the mathematical power function (Korsmeyer-Peppas model) to understand the mechanisms by which the drug release happened and to calculate the corresponding constants (Table 5). The MTX release was determined swelling-controlled, that means the reduced drug concentration gradient over the time period was compensated by an increased swelling of the nano-network which happens

A

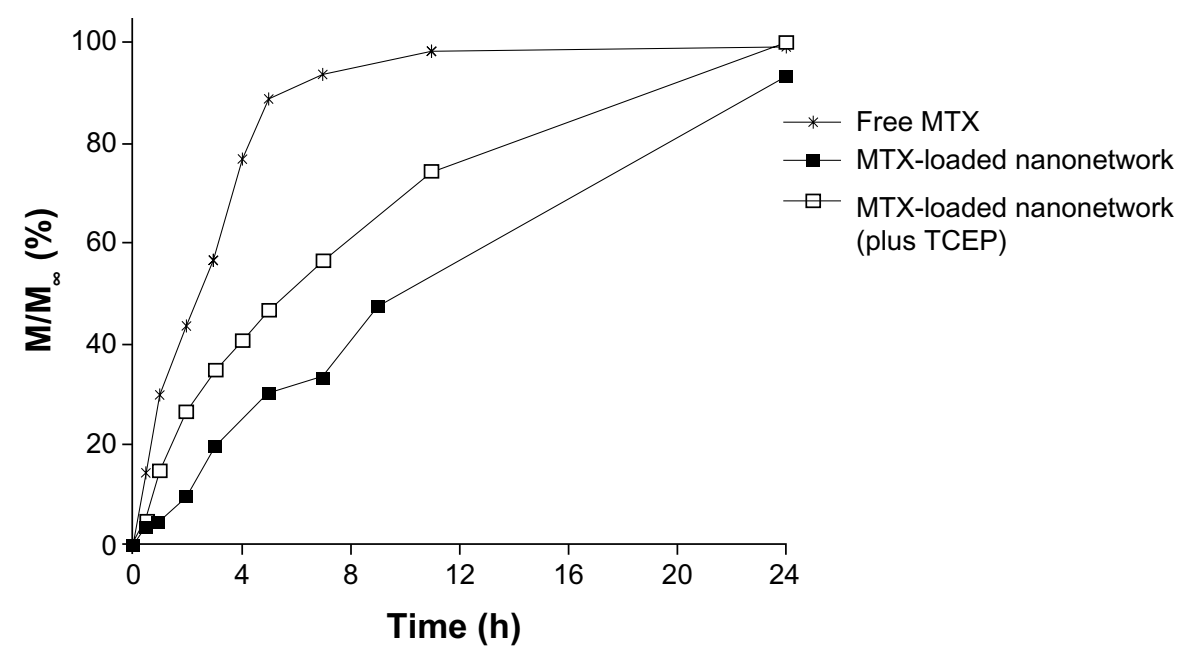

B

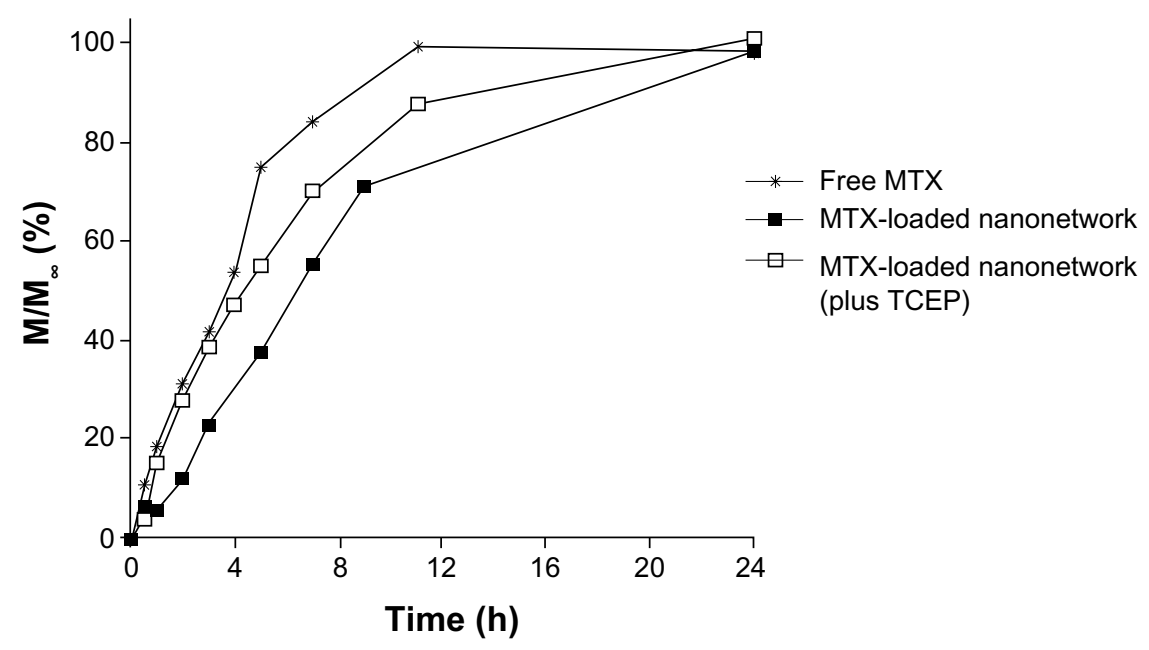

Figure 6 In vitro cumulative release of MTX from the nano-networks.

Notes: In vitro cumulative release of MTX from the nano-networks at the nominal cross-link ratio of 0.6 in $\mathrm{PBS}(\mathrm{pH}=7.4)$, or acetate buffered saline ( $\mathrm{pH}=5.5)$ without or with I mM TCEP.

Abbreviations: MTX, methotrexate; PBS, phosphate buffered saline; TCEP, tris(2-carboxyethyl)phosphine; M/M ${ }_{\infty}$, drug released. 
Table 5 Rate constants, release exponents for MTX release from nano-networks at nominal cross-link ratio

\begin{tabular}{lllll}
\hline Release condition & Rate constant $(\mathbf{K})$ & Release exponent $(\mathbf{n})$ & Lag time (hours) \\
\hline $\mathrm{pH}=7.5$ & $0.099 \pm 0.022$ & $0.92 \pm 0.09$ & $0.65 \pm 0.36$ & $\boldsymbol{R}^{\mathbf{2}}$ \\
$\mathrm{pH}=7.5+$ TCEP & $0.199 \pm 0.028$ & $0.66 \pm 0.01$ & $0.30 \pm 0.02$ & 0.998 \\
$\mathrm{PH}=5.5$ & $0.082 \pm 0.027$ & $0.88 \pm 0.19$ & $0.57 \pm 0.37$ \\
$\mathrm{pH}=5.5+$ TCEP & $0.217 \pm 0.004$ & $0.5 \mathrm{I} \pm 0.01$ & $0.53 \pm 0.03$ & 0.986 \\
\hline
\end{tabular}

Notes: The rate constants $(\mathrm{K})$ and release exponents $(\mathrm{n})$ for MTX release from the nano-networks at the nominal cross-link ratio of 0.6 (cross-linked 2 ), in PBS ( $\mathrm{pH}=7.4$ ), or acetate buffered saline $(\mathrm{pH}=5.5)$ without or with I mM TCEP.

Abbreviations: MTX, methotrexate; PBS, phosphate buffered saline; TCEP, tris(2-carboxyethyl)phosphine.

following MTX release. It was found that the nano-networks show a control over the MTX release, since $n$ was calculated to be near the value of one, especially at the physiologic $\mathrm{pH}$ of 7.5. It could be explained by the reservoir action of the nanonetwork for the negatively charged molecules, such as MTX. The effect of $\mathrm{pH}$ and the cross-linking reaction on the rate constant $(\mathrm{K})$ and $\mathrm{n}$ were not found significant $(P>0.05)$. MTX is a weak acidic drug that exhibits more solubility at $\mathrm{pH} 7.5$ than at 5.5. The lower solubility of MTX at the acidic environment of inflamed tissues can be considered as a hurdle for the delivery of MTX. The negative solubility behavior of MTX was improved most likely by a pronounced swelling of the nano-networks that compensates the reduced solubility of the drug in the relatively acidic $\mathrm{pH}$ of 5.5.

To evaluate whether reducing the disulfide containing crosslink (DTDP) can trigger MTX release from the nano-networks, the study was repeated in the release media supplemented with a reducing agent, such as TCEP, which is active in a broad range of $\mathrm{pH}$ and simulates the reducing action of glutathione. The TCEP treatment increased $\mathrm{K}$, irrespective of the medium $\mathrm{pH}$
$(P<0.05)$, that - in turn - indicates that the MTX release can be accelerated in the intracellular reducing environment.

\section{Redox-sensitive degradation}

To fabricate a stabilized redox-sensitive system for intravenous administration, bioreversible disulfide containing cross-links (DTDP) were used for the preparation of the nano-networks.

To study whether the disulfide bonds in the core of the nano-networks undergo cleavage, the empty particles were incubated in a simulated medium containing reducing agents, such as $\mathrm{NaBH}_{4}$. Figure 7 shows the ratio of free thiol to total primary amines of the nano-networks increased in the presence of the reducing agent, as the cross-link density increased. The cross-links were stable during synthesis of the nano-networks since no significant free thiol was found at the end of the reaction; nevertheless, the stable disulfide containing cross-links could be prone to glutathione mediated reduction, which predominantly occurs in the intracellular medium. ${ }^{69}$

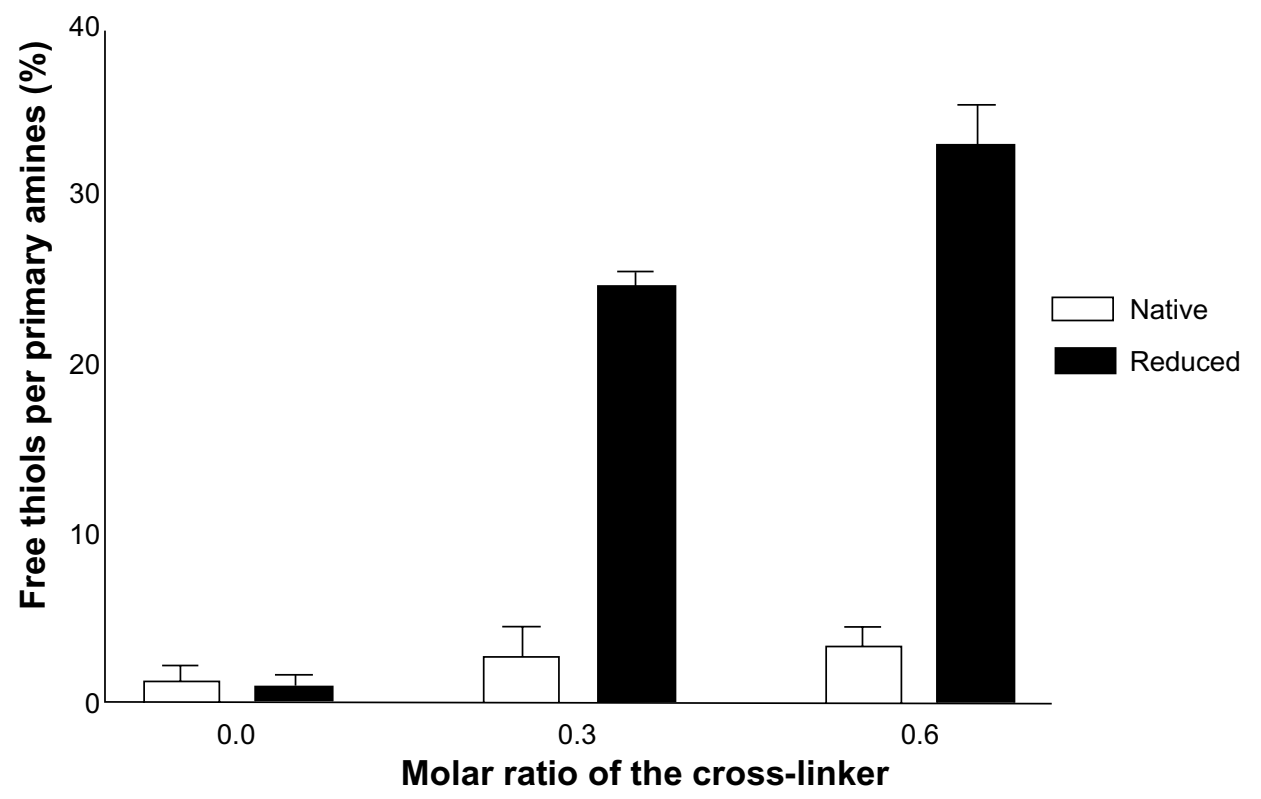

Figure 7 Redox-sensitive degradation of the nano-networks demonstrated by Ellman's assay of free thiols prior to and after addition of $0.2 \mathrm{M} \mathrm{NaBH}_{4}$. 


\section{In vitro cellular studies}

MTT assay is a sensitive method for determination of the cytotoxicity of nanostructures, since they primarily exert toxicity on the mitochondrial compartment following cellular internalization..$^{70}$ The assay was performed to compare cytotoxicity of native PEI, the PEI ionomer, or the nano-networks at $\mathrm{C}=0.3$ (cross-linked 1 ) or $\mathrm{C}=0.6$ (crosslinked 2) in the HepG2 cell line after incubation for 24 hours (Figure 8A). PEI demonstrated a concentration-dependent cytotoxicity while the PEI ionomer showed a reduced
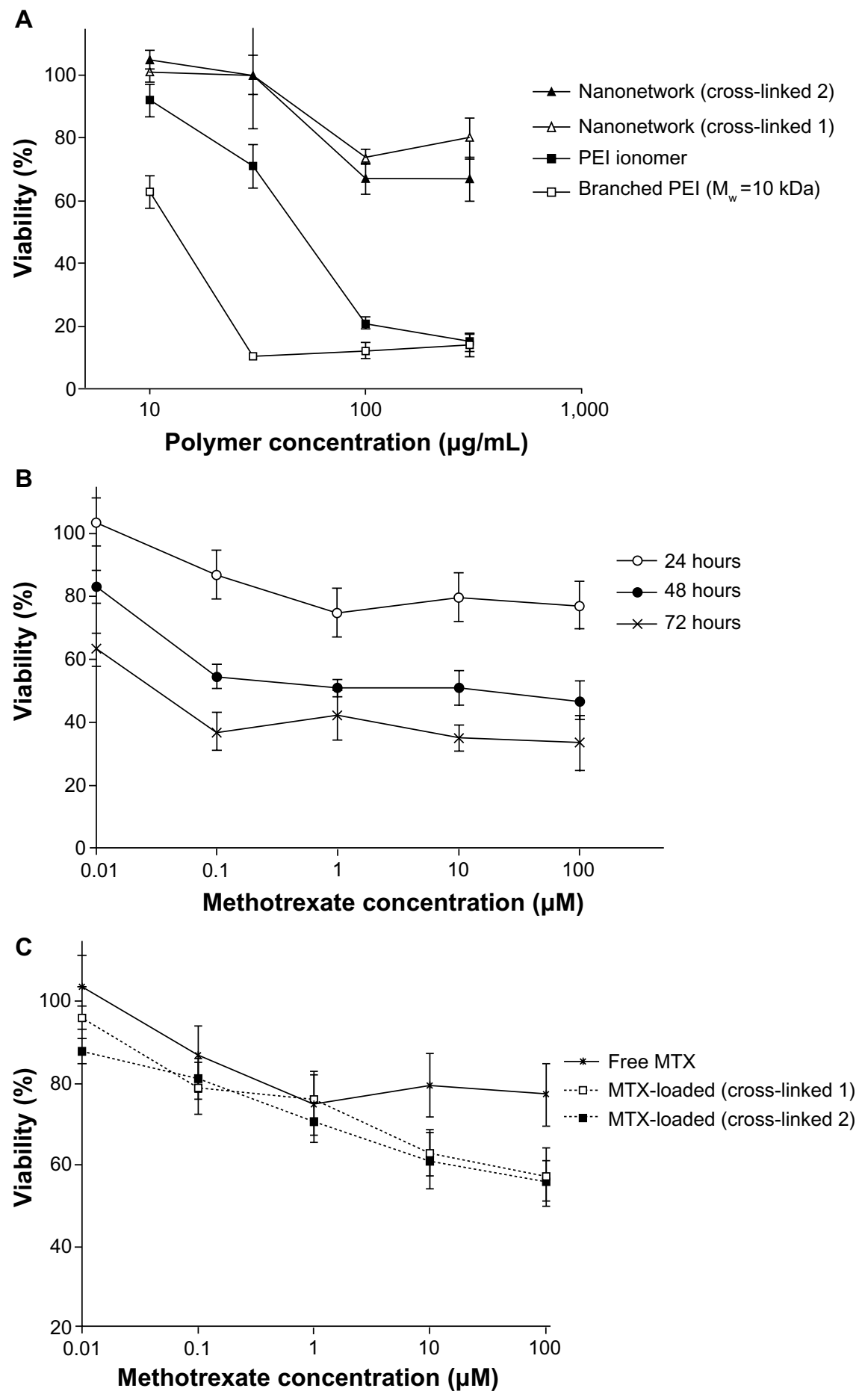

Figure 8 MTT-based cytotoxicity.

Notes: The MTT-based cytotoxicity of: (A) empty nano-networks in comparison with PEl ionomer and branched PEl after exposure for 24 hours; (B) free MTX incubated for 24, 48, and 72 hours; (C) MTX-loaded in nanonetwork versus free MTX after 24 hours of exposure at $37^{\circ} \mathrm{C}$ in $\mathrm{HepG} 2$ cell line. Cross-linked I and cross-linked 2 denote the theoretical cross-link ratios of 0.3 and 0.6 , respectively. Data are expressed as the mean \pm SD for five replicates.

Abbreviations: MTX, methotrexate; MTT, 3-(4,5-dimethylthiazol-2-yl)-2,5-diphenyltetrazolium bromide; PEI, polyethyleneimine; SD, standard deviation; Mw, weightaverage molecular weight. 
cytotoxic effect. In contrast, the nano-networks showed practically no cytotoxic effect at concentrations below $100 \mu \mathrm{g} / \mathrm{mL}$. This interesting result could be explained by the substantially reduced $\zeta$-potentials of the nano-networks and the shielding effect of the mPEG shell, as discussed by different authors. ${ }^{71,72}$

Prior to evaluating the activity of the MTX-loaded nanonetworks, the cytotoxicity of free MTX was studied as a function of the drug concentration after 24, 48, and 72 hours (Figure 8B). The incubation of HepG2 cells with increasing concentrations of MTX in the range of $0.1-100 \mu \mathrm{M}$ did not result in significant changes in cell viability at each time interval; however, a time-dependent cytotoxic effect was observed $(P<0.001)$, as previously reported, ${ }^{73}$ since MTX is a cytostatic chemotherapeutic agent that mainly inhibits cell proliferation. The toxicity on HepG2 cells was augmented for the MTX loaded in the nano-networks $(P<0.05)$, especially at the concentrations above $1 \mu \mathrm{M}$ (Figure $8 \mathrm{C}$ ), though the empty nano-networks did not demonstrate cytotoxicity. The finding might be related to the mechanisms by which free MTX transports into cells. The cellular entry of MTX is restricted to saturable mechanisms, such as the reduced folate transmembrane carrier and the folate receptor. ${ }^{74}$ Unlike free MTX, the MTX-loaded nano-networks can enter the cells via a parallel endocytic pathway. Moreover, the drug molecules that escaped from the endosomal compartment are less accessible to efflux pumps; therefore, a higher cellular accumulation of MTX and an enhanced cytotoxicity can be achieved. The issue was similarly addressed for different nanoparticulate systems. ${ }^{75,76}$

\section{Conclusion}

The nano-networks synthesized successfully through the cross-linking of the micellar template of the PEI ionomer complex, whose size distribution is controlled by $\mathrm{pH}$ and the molar ratio of a complexing metal ion, such as $\mathrm{Zn}^{2+}$. They comprise a polycation swollen core structure stabilized by a hydrophilic mPEG shell, avoiding unfavorable interactions with biological interfaces. The nano-networks exhibited some appropriate pharmaceutical properties, such as small sizes, uniformity, globular morphology, and flexibility without using high shear forces or organic solvents for manipulation. They were able to accommodate negatively charged molecules, such as MTX, efficiently featured with a higher encapsulation capacity than the corresponding polyionic micelles and a prolonged MTX release in a swelling-controlled manner; moreover, the strategy of reductive activation of nanonetwork biodegradation boosted the release rate in the simulated intracellular medium. Taken together, these observations and the enhanced antitumor activity in vitro might imply the potential application of the nano-networks for the successful delivery of MTX that should be tested in vivo.

\section{Acknowledgment}

The authors gratefully acknowledge the use of the facilities at the Center for Nanotechnology in Drug Delivery at Shiraz University of Medical Sciences and at the Nanotechnology Research Center, Tehran University of Medical Sciences. This study was funded by a Shiraz University of Medical Sciences grant for the accomplishment of the $\mathrm{PhD}$ thesis of Dr Samira Abolmaali.

\section{Disclosure}

The authors declare there is no conflict of interest.

\section{References}

1. Honglawan A, Ni H, Weissman D, Yang S. Synthesis of random copolymer based $\mathrm{pH}$-responsive nanoparticles as drug carriers for cancer therapeutics. Polym Chem. 2013;4(13):3667-3675.

2. Whitesides GM, Kriebel JK, Mayers BT. Self-Assembly and Nanostructured Materials. In: Huck WTS, editor. Nanoscale Assembly: Chemical Techniques. New York: Springer Science + Business Media; 2005:217-239.

3. Kamimura M, Kim JO, Kabanov AV, Bronich TK, Nagasaki Y. Block ionomer complexes of PEG-block-poly(4-vinylbenzylphosphonate) and cationic surfactants as highly stable, $\mathrm{pH}$ responsive drug delivery system. J Control Release. 2012;160(3):486-494.

4. Oh KT, Bronich TK, Bromberg L, Hatton TA, Kabanov AV. Block ionomer complexes as prospective nanocontainers for drug delivery. J Control Release. 2006;115(1):9-17.

5. Gohy JF, Varshney SK, Antoun S, Jérôme R. Water-soluble complexes formed by sodium poly(4-styrenesulfonate) and a poly(2-vinylpy ridinium)-block-poly(ethylenoxide) copolymer. Macromolecules. 2000;33(25):9298-9305.

6. Kabanov A, Bronich TK, Kabanov VA, Eisenberg A. Soluble stoichiometric complexes from poly(N-ethyl-4-vinylpyridinium) cations and poly(ethylen oxide)-block-polymethacrylate anions. Macromolecules. Jul 1996;29(4):6797-6802.

7. Harada A, Kataoka K. Formation of polyion complex micelles in an aqueous milieu from a pair of oppositely-charged block copolymers with poly(ethylene glycol) segments. Macromolecules. 1995;28(15): 5294-5299.

8. Bronich TK, Popov AM, Eisenberg A, Kabanov VA, Kabanov KV. Effects of block length structure of surfactant on self-assembly and solution behavior of block ionomer complexes. Langmuir. 2000;16(2):481-489.

9. Bronich TK, Nehls A, Eisenberg A, Kabanov VA, Kabanov AV. Novel drug delivery systems based on the complexes of block ionomers and surfactants of opposite charge. Colloid Surf B: Biointerfaces. 1999;16(1-4):243-251.

10. Harada A, Kataoka K. Switching by pulse electric field of the elevated enzymatic reaction in the core of polyion complex micelles. $\mathrm{JAm} \mathrm{Chem}$ Soc. 2003;125(50):15306-15307.

11. Kishimura A, Koide A, Osada K, Yamasaki Y, Kataoka K. Encapsulation of myoglobin in PEGylated polyion complex vesicles made from a pair of oppositely charged block ionomers: a physiologically available oxygen carrier. Angew Chem Int Ed Engl. 2007;46(32): 6085-6088. 
12. Kabanov VA, Kabanov AV. Interpolyelectrolyte and block ionomer complexes for gene delivery: physico-chemical aspects. Adv Drug Deliv Rev. 1998;30(1-3):49-60.

13. Kakizawa Y, Kataoka K. Block copolymer micelles for delivery of gene and related compounds. Adv Drug Deliv Rev. 2002;54(2):203-222.

14. Bronich TK, Bontha S, Shlyakhtenko LS, Bromberg L, Hatton TA, Kabanov AV. Template-assisted synthesis of nanogels from Pluronicmodified poly(acrylic acid). J Drug Target. 2006;14(6):357-366.

15. Kim JO, Sahay G, Kabanov AV, Bronich TK. Polymeric micelles with ionic cores containing biodegradable cross-links for delivery of chemotherapeutic agents. Biomacromolecules. 2010;11(4):919-926.

16. Kim JO, Kabanov AV, Bronich TK. Polymer micelles with cross-linked polyanion core for delivery of a cationic drug doxorubicin. J Control Release. 2009;138(3):197-204.

17. Oh KT, Bronich TK, Kabanov VA, Kabanov AV. Block polyelectrolyte networks from poly(acrylic acid) and poly(ethylene oxide): sorption and release of cytochrome C. Biomacromolecules. 2007;8(2):490-497.

18. Sondjaja HR, Hatton TA, Tam KC. Self-assembly of poly(ethylene oxide)-block-poly(acrylic acid) induced by $\mathrm{CaCl} 2$ : mechanistic study. Langmuir. 2008;24(16):8501-8506.

19. Bronich TK, Ouyang M, Kabanov VA, Eisenberg A, Szoka FC Jr, Kabanov AV. Synthesis of vesicles on polymer template. J Am Chem Soc. 2002;124(40):11872-11873.

20. Sanson N, Bouyer F, Destarac M, In M, Gérardin C. Hybrid polyion complex micelles formed from double hydrophilic block copolymers and multivalent metal ions: size control and nanostructure. Langmuir. 2012;28(8):3773-3782.

21. Sanson N, Bouyer F, Gérardin C, In M. Nanoassemblies formed from hydrophilic block copolymers and multivalent ions. Phys Chem Chem Phys. 2004;6(7):1463-1466.

22. An L, Wang Y, Liu X, et al. Block ionomer complex micelles based on the self-assembly of poly(ethylene glycol)-block-poly(acrylic acid) and $\mathrm{CdCl}_{2}$ for anti-tumor drug delivery. Chem Pharm Bull (Tokyo). 2011;59(5):559-563.

23. Solomatin SV, Bronich TK, Bargar TW, Eisenberg A, Kabanov VA, Kabanov AV. Environmentally responsive nanoparticles from block ionomer complexes: effects of $\mathrm{pH}$ and ionic strength. Langmuir. 2003; 19(19):8069-8076

24. Kunath K, von Harpe A, Fischer D, et al. Low-molecular-weight polyethylenimine as a non-viral vector for DNA delivery: comparison of physicochemical properties, transfection efficiency and in vivo distribution with high-molecular-weight polyethylenimine. J Control Release. 2003;89(1):113-125.

25. Bronstein LM, Sidorov SN, Gourkova AY, et al. Interaction of metal compounds with 'double-hydrophilic' block copolymers in aqueous medium and metal colloid formation. Inorganica Chimica Acta. 1998;280(1-2):348-354.

26. Sidorov SN, Bronstein LM, Valetsky PM, et al. Stabilization of metal nanoparticles in aqueous medium by polyethyleneoxidepolyethyleneimine block copolymers. J Colloid Interface Sci. 1999;212(2):197-211.

27. Bhattacharjee S, Dong J, MaY, et al. Formation of high-capacity proteinadsorbing membranes through simple adsorption of poly(acrylic acid)containing films at low pH. Langmuir. 2012;28(17):6885-6892.

28. Vignesh G, Arunachalam S, Vignesh S, James RA. BSA binding and antimicrobial studies of branched polyethyleneimine-copper(II) bipyridine/phenanthroline complexes. Spectrochim Acta A Mol Biomol Spectrosc. 2012;96:108-116.

29. Wu S, Zhang L, Yang K, Liang Z, Zhang L, Zhang Y. Preparing a metalion chelated immobilized enzyme reactor based on the polyacrylamide monolith grafted with polyethylenimine for a facile regeneration and high throughput tryptic digestion in proteomics. Anal Bioanal Chem. 2012;402(2):703-710.

30. Dacarro G, Cucca L, Grisoli P, Pallavicini P, Patrini M, Taglietti A. Monolayers of polyethilenimine on flat glass: a versatile platform for cations coordination and nanoparticles grafting in the preparation of antibacterial surfaces. Dalton Trans. 2012;41(8):2456-2463.
31. Chertok B, David AE, Yang VC. Polyethyleneimine-modified iron oxide nanoparticles for brain tumor drug delivery using magnetic targeting and intra-carotid administration. Biomaterials. 2010;31(24): 6317-6324.

32. Müller M, Keßler B, Fröhlich J, Poeschla S, Torger B. Polyelectrolyte complex nanoparticles of poly(ethyleneimine) and poly(acrylic acid): preparation and applications. Polymers (Basel). 2011;3(2): $762-778$.

33. Bontha S, Kabanov AV, Bronich TK. Polymer micelles with crosslinked ionic cores for delivery of anticancer drugs. J Control Release. 2006;114(2):163-174

34. Bronstein LM, Kostylev M, Shtykova E, et al. Mixed Co/Fe oxide nanoparticles in block copolymer micelles. Langmuir. 2008;24(21): 12618-12626.

35. Vinogradov SV, Bronich TK, Kabanov AV. Self-assembly of polyamine-poly(ethylene glycol) copolymers with phosphorothioate oligonucleotides. Bioconjug Chem. 1998;9(6):805-812.

36. Nguyen HK, Lemieux P, Vinogradov SV, et al. Evaluation of polyether-polyethyleneimine graft copolymers as gene transfer agents. Gene Ther. 2000;7(2):126-138.

37. Frankel AE. Reducing the immune response to immunotoxin: commentary re R Hassan et al, pretreatment with rituximab does not inhibit the human immune response against the immunogenic protein LMB-1. Clin Cancer Res. 2004;10:16-18. Clinical Cancer Research. 2004;10(1):13-15.

38. Ghiamkazemi S, AmanzadehA, Dinarvand R, Rafiee-Tehrani M,Amini M. Synthesis, and characterization, and evaluation of cellular effects of the FOL-PEG-g-PEI-GAL nanoparticles as a potential non-viral vector for gene delivery. J Nanomater. 2010;50.

39. Merdan T, Kunath K, Petersen H, et al. PEGylation of poly(ethylene imine) affects stability of complexes with plasmid DNA under in vivo conditions in a dose-dependent manner after intravenous injection into mice. Bioconjug Chem. 2005;16(4):785-792.

40. Mao S, Neu M, Germershaus O, et al. Influence of polyethylene glycol chain length on the physicochemical and biological properties of poly(ethylene imine)-graft-poly(ethylene glycol) block copolymer/ SiRNA polyplexes. Bioconjug Chem. 2006;17(5):1209-1218.

41. Fischer D, Osburg B, Petersen H, Kissel T, Bickel U. Effect of poly(ethylene imine) molecular weight and pegylation on organ distribution and pharmacokinetics of polyplexes with oligodeoxynucleotides in mice. Drug Metab Dispos. 2004;32(9):983-992.

42. Purcell WT, Ettinger DS. Novel antifolate drugs. Curr Oncol Rep. 2003;5(2):114-125

43. Grim J, Chládek J, Martínková J. Pharmacokinetics and pharmacodynamics of methotrexate in non-neoplastic diseases. Clin Pharmacokinet. 2003;42(2):139-151.

44. Widemann BC, Adamson PC. Understanding and managing methotrexate nephrotoxicity. Oncologist. 2006;11(6):694-703.

45. Abelson HT, Fosburg MT, Beardsley GP, et al. Methotrexate-induced renal impairment: clinical studies and rescue from systemic toxicity with high-dose leucovorin and thymidine. J Clin Oncol. 1983;1(3): 208-216.

46. Rodenhuis S, McGuire JJ, Narayanan R, Bertino JR. Development of an assay system for the detection and classification of methotrexate resistance in fresh human leukemic cells. Cancer Res. 1986;46(12 Part 1):6513-6519.

47. Koch AE, Distler O. Vasculopathy and disordered angiogenesis in selected rheumatic diseases: rheumatoid arthritis and systemic sclerosis. Arthritis Res Ther. 2007;9 Suppl 2:S3.

48. Koning GA, Schiffelers RM, Wauben MH, et al. Targeting of angiogenic endothelial cells at sites of inflammation by dexamethasone phosphate-containing RGD peptide liposomes inhibits experimental arthritis. Arthritis Rheum. 2006;54(4):1198-1208.

49. Gaffo A, Saag KG, Curtis JR. Treatment of rheumatoid arthritis. Am J Health Syst Pharm. 2006;63(24):2451-2465.

50. Levick JR. Hypoxia and acidosis in chronic inflammatory arthritis; relation to vascular supply and dynamic effusion pressure. J Rheumatol. 1990;17(5):579-582. 
51. Trachsel E, Bootz F, Silacci M, Kaspar M, Kosmehl H, Neri D. Antibody-mediated delivery of IL-10 inhibits the progression of established collagen-induced arthritis. Arthritis Res Ther. 2007; 9(1):R9.

52. Abolmaali SS, Tamaddon AM, Dinarvand R. A review of therapeutic challenges and achievements of methotrexate delivery systems for treatment of cancer and rheumatoid arthritis. Cancer Chemother Pharmacol. 2013;71(5):1115-1130.

53. Abolmaali SS, Tamaddon AM, Dinarvand R. Nano-hydrogels of methoxy polyethylene glycol-grafted branched polyethyleneimine via biodegradable cross-linking of $\mathrm{Zn}^{2+}$-ionomer micelle template. J Nanopart Res. 2013;15(12):1-21.

54. Choi JH, Choi JS, Suh H, Park JS. Effect of poly(ethylene glycol) grafting on polyethylenimine as a gene transfer vector in vitro. BulletinKorean Chemical Society. 2001;22(1):46-52.

55. Colombo PR, Bettini R, Santi P, De Ascentiis A, Peppas NA. Analysis of the swelling and release mechanisms from drug delivery systems with emphasis on drug solubility and water transport. $J$ Control Release. 1996;39(2):231-237.

56. Bir K, Crawhall JC, Mauldin D. Reduction of disulfides with sodium and potassium borohydrides and its application to urinary disulfides. Clin Chim Acta. 1970;30(1):183-190.

57. Mosmann T. Rapid colorimetric assay for cellular growth and survival: application to proliferation and cytotoxicity assays. J Immunol Methods. 1983;65(1-2):55-63.

58. Matsuda T, Annaka M. Salt effect on complex formation of neutral/ polyelectrolyte block copolymers and oppositely charged surfactants. Langmuir. 2008;24(11):5707-5713.

59. Kim JO, Nukolova NV, Oberoi HS, Kabanov AV, Bronich TK. Block ionomer complex micelles with cross-linked cores for drug delivery. Polym Sci Ser A Chem Phys. 2009;51(6):708-718.

60. Bronich TK, Cherry T, Vinogradov SV, Eisenberg A, Kabanov VA, Kabanov AV. Self-assembly in mixtures of poly(ethylene oxide)graft-poly(ethyleneimine) and alkyl sulfates. Langmuir. 1998;14(21): 6101-6106.

61. Bronich TK, Vinogradov SV, Kabanov AV. Interaction of nanosized copolymer networks with oppositely charged amphiphilic molecules. Nano Lett. 2001;1(10):535-540.

62. Sahiner N, Godbey WT, McPherson GL, John VT. Microgel, nanogel and hydrogel-hydrogel semi-IPN composites for biomedical applications: synthesis and characterization. Colloid Polym Sci. 2006;284(10): 1121-1129.

63. Jeong YI, Seo DH, Kim DG, et al. Methotrexate-incorporated polymeric micelles composed of methoxy poly(ethylene glycol)-grafted chitosan. Macromolecular Research. 2009;17(7):538-543.
64. Kabanov AV, Vinogradov SV. Nanogels as pharmaceutical carriers: finite networks of infinite capabilities. Angew Chem Int Ed Eng. 2009;48(30):5418-5429.

65. Ji J, Wu D, Liu L, Chen J, Xu Y. Preparation, evaluation, and in vitro release of folic acid conjugated $O$-carboxymethyl chitosan nanoparticles loaded with methotrexate. J Appl Polym Sci. 2012;125(S2): E208-E215.

66. Kohler N, Sun C, Wang J, Zhang M. Methotrexate-modified superparamagnetic nanoparticles and their intracellular uptake into human cancer cells. Langmuir. 2005;21(19):8858-8864.

67. Jingou J, Shilei H, Weiqi L, Danjun W, Tengfei W, Yi X. Preparation, characterization of hydrophilic and hydrophobic drug in combine loaded chitosan/cyclodextrin nanoparticles and in vitro release study. Colloids Surf B Biointerfaces. 2011;83(1):103-107.

68. Liang LS, Jackson J, Min W, Risovic V, Wasan KM, Burt HM. Methotrexate loaded poly(L-lactic acid) microspheres for intra-articular delivery of methotrexate to the joint. J Pharm Sci. 2004;93(4):943-956.

69. Yang J, Chen H, Vlahov IR, Cheng JX, Low PS. Evaluation of disulfide reduction during receptor-mediated endocytosis by using FRET imaging. Proc Natl Acad Sci U S A. 2006;103(37):13872-13877.

70. Denizot F, Lang R. Rapid colorimetric assay for cell growth and survival. Modifications to the tetrazolium dye procedure giving improved sensitivity and reliability. J Immunol Methods. 1986;89(2):271-277.

71. Petersen H, Fechner PM, Martin AL, et al. Polyethylenimine-graftpoly(ethylene glycol) copolymers: influence of copolymer block structure on DNA complexation and biological activities as gene delivery system. Bioconjug Chem. 2002;13(4):845-854.

72. Neu M, Sitterberg J, Bakowsky U, Kissel T. Stabilized nanocarriers for plasmids based upon cross-linked poly(ethylene imine). Biomacromolecules. 2006;7(12):3428-3438.

73. Nogueira DR, Tavano L, Mitjans M, Pérez L, Infante MR, Vinardell MP. In vitro antitumor activity of methotrexate via $\mathrm{pH}$-sensitive chitosan nanoparticles. Biomaterials. 2013;34(11):2758-2772.

74. Takimoto $\mathrm{CH}$. New antifolates: pharmacology and clinical applications. Oncologist. 1996;1(1 and 2):68-81.

75. Karasulu HY, Kantarci G, Karaca B, Armagan V, Güneri T, Göker E. Determining the cytotoxicity of methotrexate-loaded microemulsion on human breast, ovarian, and prostate carcinoma cell lines: a new modality for an old drug. Drug Dev Res. 2009;70(1):49-56.

76. Moura JA, Valduga CJ, Tavares ER, Kretzer IF, Maria DA, Maranhão RC. Novel formulation of a methotrexate derivative with a lipid nanoemulsion. Int J Nanomedicine. 2011;6:2285-2295.
International Journal of Nanomedicine

\section{Publish your work in this journal}

The International Journal of Nanomedicine is an international, peerreviewed journal focusing on the application of nanotechnology in diagnostics, therapeutics, and drug delivery systems throughout the biomedical field. This journal is indexed on PubMed Central, MedLine, CAS, SciSearch ${ }^{\circledR}$, Current Contents ${ }^{\circledR} /$ Clinical Medicine,

\section{Dovepress}

Journal Citation Reports/Science Edition, EMBase, Scopus and the Elsevier Bibliographic databases. The manuscript management system is completely online and includes a very quick and fair peer-review system, which is all easy to use. Visit http://www.dovepress.com/ testimonials.php to read real quotes from published authors. 